\title{
Ueber einen neuen anaëroben Bacillus und seine Beziehungen zum Botulismus.
}

\author{
Von
}

Prof. Dr. F. van Ermengem

in Gent (Belgien).

(Ilierzn Taf. 1-III.)

Die pathologisehen Erscheinungen, mit dem Namen des Botulismus ocer Alliantiasis bezeichnet, verdienen einen besonderen Platz unter den Erkrankungen, welche durch den Genuss von gewissen Nahrungsmitteln erzeugt werden. Seit Ende vorigen Jahrhunderts haben sie das Interesse der Toxicologen wegen ihres sonderbaren Typus und ihrer immerhin noch dunklen Pathogenese erregt, und wegen ihrer Häufigkeit, hohen Gefährlichkeit und der Unsicherheit ihrer Prophylaxe stets die Aufmerksamkeit der öffentlichen Hygiene auf sich gelenkt.

In der letzten Zeit bot sich uns die Gelegenheit eine Reihe von Fällen, dèren Aehnlichkeit mit dem classischen Botulismus eine ausgesprochene war, einer gründlichen Untersuchung unterziehen zu können. Vorliegende Mittheilung stellt einen Abriss einer ausführlichen demnächst erscheinenden Arbeit ${ }^{1}$ dar.

Unsere Beobachtungen betreffen eine Art von Fleischvergiftungen, welche seltener werden und deren Aetiologie bis jetzt noch nicht mit Hülfe der modernen Untersuchungsmittel nachgewiesen ist. Deshalb möchten wir unsere Resultate weiteren Kreisen mittheilen, um eventuell ihre Bestätigung zu erhalten.

1 S. Contribution à l'étude des intoxications alimentaires. - Recherches sur des accidents à caractères botuliniques. Archives de Pharmacodynamie. Vol. III. Fasc. 3 à 6. Mars et Juillet 1897. 
Im Laufe des Decembers 1895 trat in einem Dorfe im Henegau, Ellezelles genannt, unter den Mitgliedern eines Musikvereins, die an einer Trauerfeier theilnahmen, eine eigenartige Epidemie auf. Mit wenigen Ausnahmen erkrankten alle. Drei starben in einer Woche, wenigstens zehn schwebten in Todesgefahr.

Als Ursache der Erkrankung wurde der Genuss eines rohen Schinkens angesehen. Kein einziger der Musiker, welcher von diesem Fleische nicht gegessen hatte, ist in seiner Gesundheit irgendwie gestört worden. In den folgenden Tagen nach dem Festmahl, noch bevor durch die ernstlichen Erscheinungen die Aufmerksamkeit auf den Schinken gelenkt wurde, erkrankten noch mehrere Personen unter denselben Krankheitssymptomen. Auch sie hatten von dem verdächtigen Fleische genossen.

Die Verstorbenen und die Erkrankten hatten ungefähr $200 \mathrm{grm}$, speciell von dem Muskelfleisch, weniger vom Speck genossen.

Die meisten erkrankten ziemlich spät, etwa 20 bis 24 Stunden, einige erst 36 Stunden nach der Mahlzeit. Nur drei fühlten sich früher unwohl; fast beim Verlassen des Mahles zeigten sie schon Verdauungsstörungen: Uebelkeit, Erbrechen, kolikartige Schmerzen u. s. w. Mehrere empfanden am folgenden oder zweiten Tage Magenschmerzen, erbrachen wiederholt, zuerst nur Speisereste, darauf gallertartige, schwärzliche Massen. Diarrhöischer Stuhlgang wurde nicht beobachtet, im Gegentheil trat unmittelbar eine hartnäckige Verstopfung auf, welche später erst durch energische Abführmittel gehoben wurde. Die ersten spontan oder künstlich hervorgerufenen Entleerungen waren gewöhnlich schwarz und viscös. Jedoch zwei ziemlich schwer erkrankte Personen hatten während der zwei ersten Tage flüssigen Stuhlgang.

Charakteristische Sehstörungen traten 36 bis 48 Stunden nach der Mahlzeit in allen Fällen auf. Die Kranken klagten über Verschleierung der Augen wie durch einen Nebel; bald wurden die Anwesenden nicht mehr erkannt und die aus der Nähe betrachteten Objecte schienen undeutlich. $\mathrm{Zu}$ gleicher Zeit hatten die meisten mehr oder wèniger ausgesprochene binoculäre Diplopie.

Neben diesen subjectiven Erscheinungen wurden starke Pupillenerweiterung mit totaler Reactionslosigkeit derselben auf Lichtreiz, Ptosis der beiden Augenlider und eine sonderbare, durch die Unbeweglichkeit der Bulbi hervorgerufene Starrheit des Blickes beobachtet. Endlich in zwei oder drei Fällen thränten die Augen, welche glänzend und injicirt waren.

Die Kranken klagten sehr über brennenden Durst und hatten das Gefühl einer Constriction, einer Erwürgung am Halse. Das Schlingen war erschwert, nicht selten in hohem Grade, so dass die Einnahme von Flüssigkeiten, speciell aber von festen Speisen recht schwierig und selbst ganz unmöglich wurde und jedes Mal von bedenklichen Erstickungsanfällen begleitet war.

Nasen-, Mund- und Pharynxschleimhäute waren stark geröthet und bedeckt von einem anomalen Secretproduct. Die meisten der Schwererkrankten wurden durch graue dickflüssige Schleimmassen sehr geplagt, welche sich im Schlunde sammelten und quälende Husten- und Erstickungsanfälle hervorriefen. Es trat erst Ruhe ein, als dieselben mittels eines Pinsels abgewischt 
wurden. Bei anderen schien die Speichelsecretion ganz zu sistiren, die Schleimhäute waren trocken und glänzend.

Im Allgemeinen war die Stimme dumpf und nicht selten trat totale Aphonie ein, die Articulation war oft erschwert. „Der Kranke spricht, als ob die Zunge halb gelähmt sei.“ Einige hatten croupartigen Husten, langandauerndes Unvermögen Harn zu lassen, bisweilen Dysurie.

Trotz dieser schweren Vergiftungssymptome schienen die Athmungsund Kreislauforgane nicht sehr alterirt zu sein. Pulszahl überstieg nie 90, die Temperatur blieb normal, die Respiration ruhig. Nur in den tödtlichen Fällen sah man intensive Störungen in der Herzinnervation und Bulbärerscheinungen: Collaps, dyspnoische Anfälle, kleiner und unregelmässiger Puls u. s. w. wurden immer einige Stunden vor dem Tode beobachtet.

Das Bewusstsein wie die allgemeine Sensibilität blieben während des ganzen Verlaufes der Erkrankung intact, nur im Falle von tödtlichem Ausgang trat im letzten Stadium ein comatöser Zustand oder leichtes Delirium auf. Manche Kranke zeigten in den ersten Tagen andauernde Schlaflosigkeit.

Fndlich sei erwähnt,. dass die Extremitäten wie die Rumpfmusculatur weder vollständige Lähmung noch Atrophie zeigten. Nur klagten alle Schwererkrankten über Mattigkeit, eine extreme Ermüdung nach wenigen Bewegungen. Die Muskelschwäche war eine allgemeine und der Kräfteverfall bei den meisten derart, dass Wochen lang das Bett gehütet werden musste.

Der Verlauf dieser so charakteristischen Erkrankung war wesentlich ein protrahirter, wenn er in Heilung überging. Erst nach 2 bis 3 Wochen besserten sich die Augensymptome: die Pupillenerweiterung nahm zur Hälfte ab; das Sehen in der Nähe wurde allmählich distincter; die halbgelähmten Augenlider hoben sich mehr und mehr zurück; das Doppeltsehen trat nur auf, wenn der Kranke mit den beiden Augen nach der Seite fixirte. Jedoch dauerte die Accommodationslähmung noch lange Zeit nach dem Verschwinden aller anderen Symptome fort. Verschiedene Kranke konnten fünf Monate nachher nur mit Hülfe einer Brille lesen; das normale Sehen stellte sich erst nach 6 bis 8 Monaten wieder ein. Die Schlingbeschwerden, der anomale Speichelfluss, die Verstopfung u. s. w. schwanden ebenfalls allmählich.

Von den 34 Musikern, welche am 14. December zusammen speisten, erkrankte ein Drittel sehr ernstlich, zehn leichter Erkrankte zeigten obige Symptome in abgeschwächter Form: Uebelsein, Trockenheit und Constrictionsgefühl im Halse, Pupillenerweiterung, Gesichtsabschwächung, Schlingbeschwerden für feste Speisen, Verstopfung. Bettruhe war nicht nöthig, aber während 3 Wochen ungefähr bestand eine allgemeine Schwäche und eine geringe Arbeitsfähigkeit. Unter ihnen befanden sich diejenigen, welche weniger Schinken, etwa eine Scheibe (Fett- und Fleischsubstanz) vor 60 bis $70 \mathrm{grm}$, genossen hatten, kräftige Personen oder solche, die bald nach dem Essen Indigestionsstörungen gezeigt hatten.

Die übrigen Mitglieder der Gesellschaft blieben ganz gesund und zwar diejenigen, welche entweder nur Schinkenfett oder eine minimale Menge Schinkenfleisch gegessen hatten.

Die uns mitgetheilten Protocolle der gerichtlichen Obductionen von zwei Verstorbenen erwähnten keine charakteristischen Veränderungen der 
Organe, nur eine auffallende Hyperämie der Nieren, Leber, Hirnhäute u. s. w., eine Erweichung und ausserordentliche Rissigkeit der Magenwände.

Es wurden uns Organe einer Leiche zur Verfügung gestellt. Sie schienen durch cadaverōse Processe wenig angegriffen, obwohl der Tod vor sieben Tagen erfolgt war. Die Nieren waren sehr hyperämisch, die Leber zeigte starke Degeneration, das Gehirn wies einige punktförmige Hämorrhagieen auf.

Auf Schnitten der Leber sah man eine fettige Degeneration der Leberzellen, sowie an verschiedenen Stellen leukocytäre Emigration zwischen den Acinis. Veränderungen der Nieren waren weniger ausgesprochen. Ausser der Hyperämie waren nur einige kleine Infarcte und fibrinöse Exsudate innerhalb der Bowman'schen Kapseln zu beobachten. Weder Cylinder noch Desquamation der Drüsenepithelien waren vorhanden. Milzpulpa blutreich, die Follikel ziemlich klein. Keine weiteren Befunde.

Die besten Färbungsmethoden wiesen in sämmtlichen Organen nur die Anwesenheit wenig zahlreicher und zerstreuter Mikroorganismen, einige kurze Bacillen, auf. Auf Plattenculturen mit Leber- und Nierparenchym entwickelten sich nur gewöhnliche Bakterien. Aus der Milz dagegen konnte ein anaëober Bacillus gezüchtet werden, dessen Verhältniss zum Botulismus später dargelegt werden wird.

Das Schwein, von welchem der verdächtige Schinken stammte, war an 2. August Mittags geschlachtet worden; das Thier wurde als gesund befunden, das Fleisch aber nicht weiter expertisirt. Die Angehörigen des Besitzers des Schweines hatten das frische Fleisch genossen, ohne irgendwelche Störung des Allgemeinbefindens.

Das zur Conservirung bestimmte Fleisch wurde 24 Stunden nach dem Schlachten eingesalzen. Wie behauptet wird, geschah die Einsalzung unter den gewöhnlichen Cautelen.

Vor dem am 14. December stattgefundenen fatalen Festmahl war schon zum grössten Theil das Fleisch, unter Anderem einer der Schinken, genossen und hatte nicht die geringste Störung hervorgerufen. Am 15. und 16. December hatten noch zwei Personen von demselben ungekochten Fleisch gegessen, ohne in ihrer Gesundheit irgendwie geschädigt zu werden. Von dem verdächtigen Schinken aber wurde zum ersten Mal beim Gastmahl des Musikvereins am 14. December genossen.

Die zwei Schinken, sowie die verschiedenen Fleischstücke sind in demselben Fass und am selben Tage eingesalzen worden. Es ist festgestellt, dass der Schinken, dem die Erkrankung zugeschrieben wurde, auf dem Boden des Fasses lag, und er allein in das Salzwasser tauchte. Direct darauf, nur durch eine Schicht von Speckstücken getrennt, befand sich der zweite Schinken. 
Reste ron beiden Schinken wurden uns znr Untersuchung übermittelt. Der Schinken, welcher als unschädlich angesehen werden konnte, war theilweise verfault. An mehreren Stellen, besonders in der Umgebung des Knochens war das Fleisch ziemlich stark verdorben; es reagirte positiv auf alle die von Eber (1) angegebenen Criterien der stinkenden Fäulniss und enthielt zahlreiche Bakterien. An anderen Stellen, wo das Fleisch gesund aussah, fehlten die Mikroorganismen vollständig und die Muskelfasern hatten ihre normale Structur.

Das uns zugeschickte Stück des verdächtigen Schinkens, welcher grösstentheils für die gerichtlich-chemische Untersuchung verarbeitet wurde, war nur faustgross und wog ohne Knochen ea. $180 \mathrm{gm}$. Von Fäulnissgeruch war nichts wahrzunehmen, aber wohl ein ausgesprochen scharfer ranziger Geruch, der verdorbener Butter ähnlich. Die Musculatur sah gut aus, war aber etwas blassfarbig, gleich dem Fleische, welches längere Zeit in Wasser macerirt hat; das Gewebe war gelockert, leichter zerreissbar wie gewöhnlich, ohne jedoch klebrig zu sein. Weder in der Umgebung des Knochens noch in den peripherischen Schnitten waren verfaulte Theile aufzufinden. Der Speck war fest, weissröthlich und zeigte nichts anomales ausser dem ranzigen Buttersäuregeruch.

Der Wirth, welcher den Schinken verkaufte und zerschnitten hatte, erklärte nichts Abnormes am Fleisch beobachtet zu haben und versicherte, dass kein unangenehmer Geruch sich bemerkbar gemacht habe. Die Consumenten fanden dagegen fast einstimmig, dass der Schinken einen schlechten Geschmack gehabt habe. Der Geruch jedoch ist ihnen nicht aufgefallen. Das Gutachten des vereideten Chemikers bestätigt ebenfalls, dass das verdächtigte Fleiseh nicht verfault war.

Zahlreiche auf Deckgläsern mit Muskel- und Specksaft gemachte Präparate wiesen keine oder nur sehr spärliche Bakterien auf. In dem Knochenmark, auf Deckgläsern ausgestrichen, wurden Bakterien ebenfalls vermisst. Die Muskelfasern waren auf Schnittpräparaten grösstentheils abgeblasst, aber noch ziemlich dentlich gestreift. Hier und da sind sie zerrissen oder quer eingekerbt; andere Muskelbündel sind deformirt, iu eine hyaline Masse umgewandelt, wenig färbbar, mit unregelmässigen und ausgebuchteten Umrissen, als ob die Muskelfasern durch irgendwelche Flüssigkeit theilweise aufgequollen wären. Andere sehen wiederum wie angefressen und aufgelöst aus. Das fettige Gewebe wies nichts Anomales auf.

Wie wir später zeigen werden, enthielt dieser Schinken an verschiedenen Stellen äusserst zablreiche Mikroorganismen, welche sich durch die anaërobe Cultur nachweisen liessen und sich zu grossen sporentragenden Bacillen auf den Platten ausbildeten. Auf Grund dieses Befundes wurde die Schnittuntersuchung 
wieder anfgenommen und entsprechende Färbungsmethoden angewandt. Mittels Ziehl'scher Lösung zeigten sich dann zwischen den Muskelbündeln Gruppen und Häufchen von kleinen länglichen, ellipsoïdalen refringirenden Körperchen, welche zweifellos als freie Sporen zu deuten sind. (Vgl. Taf. I, Figg. 1 u. 2.)

Wenn man den zu Ellezelles beobachteten Symptomencomplex mit den unter dem Namen des Botulismus bekannten Erkrankungen vergleicht, ist es unschwer zahlreiche Analogieen sofort zu erkennen. Jedoch bestehen zwischen dieser schon längst beschriebenen Fleischvergiftung und der unserigen einige sehr geringe Unterschiede, welche wir nicht versãumen wollen noch hervorzuheben.

Zuerst aber möchten wir einige falsche Auffassungen eliminiren, welche noch immer über die Frage der Fleischvergiftung im Umlauf sind und dieselben sehr verwirren. Der Botulismus bezeichnete längere Zeit hindurch eine besondere Art von Erkrankungen, hervorgerufen durch den Genuss von Würsten, speciell Blutwürsten, welche in Schwaben und den benachbarten Theilen Bayerns und Badens fabricirt werden.

Es wurde alsbald erkannt, dass andere Lebensmittel, wie Schinken, Fleischconserven und selbst Fische dieselben Erkrankungsformen gelegentlich verursachen können. Die eigenthümlichen Erscheinungen wurden sodann unter derselben Benennung, der des „Botulismus“, beschrieben.

In neuerer Zeit haben leider manche Forscher diese Bezeichnung noch mehr verallgemeinert und sprechen den unter diese Rubrik gruppirten Erkrankungen jede Specifität ab. Alle Störungen, durch Fleischgenuss hervorgerufen, welcher Art auch die Conservirung und die Vorbereitung des Nahrungsmittels gewesen, gleichwohl ob es frisch, roh, gar oder conservirt genossen worden, ob es von kranken oder gesuuden Thieren abstammte, werden von diesen Autoren unter den Botulismus gerechnet. Da sie der Verschiedenheit des klinischen Bildes und der gesetzten Läsionen, sowie dem ätiologischen Moment keine Rechnung tragen, nehmen sie kein Bedenken, total verschiedene Krankheitsbilder für identisch zu erklären. Der Botulismus sollte sich also äussern: bald durch eine nervöse fieberlose Krankheit, wofür die Erscheinungen von Ellezelles ein frappantes Beispiel liefern, bald durch fieberhafte Gastroenteritis, Cholera nostras ähnlich Durchfälle u. s. w.

Solche Verwirrungen sind mit dem heutigen wissenschaftlichen Standpunkt nicht vereinbar und der weiteren Lösung der Frage entschieden nachtheilig. So erklärt es sich leicht, dass die gegen die Fleischrergiftungen vorgeschriebenen prophylaktischen Massregeln so verschiedenartiger Natur und selbst zum Widerspruch herausfordern. 
Uns scheint es, dass man sowohl den engeren etymologischen, als den heutigen zu viel verallgemeinerten Sinn des Wortes Botulismus fallen lassen muss und diese Bezeichnung bei all denjenigen Erkrankungen anwenden soll, welche durch animalische oder vegetabilisehe Nahrung hervorgerufen werden, sobald sie sich durch die eigenartigen, klinisch leicht zu diagnosticirenden Erscheinungen der altbekannten "Wurstvergiftung" kennzeichnen.

Schon im Jahre 1870 betonte Müller (2) die Verschiedenheit der durch Würste bedingten Krankheitsbilder und schlug vor, sie nach ihren klinischen Analogieen zu ordnen. Er trennte diejenigen Fälle, in denen das eigentliche Wurstgift allein zu beschuldigen und welchen der Name Botulismus zu geben sei, von denjenigen ab, wo es sich um eine Vergiftung durch Fäulnissproducte handelte. Fine dritte Gruppe umfasste die gemischten, theils durch das botulinische Agens, theils durch putride Gifte hervorgerufenen Erkrankungen. Endlich wurden in eine vierte Gruppe die Fälle zusammengefasst, die durch Fleischgenuss erkrankter Thiere bedingt werden.

Diese Classification kann heute noch, nicht nur für die eigentlichen Wurstvergiftungen, sondern auch im Allgemeinen für alle sogenannten "Fleischvergiftungen" als zutreffend betrachtet werden. Jedenfalls muss unbedingt der Botulismus von den durch gastro-enteritische Symptome sich fast ausschliesslich äussernden Krankheiten unterschieden werden.

In den meisten Fällen handelt es sich um Erkrankungen, welche nach dem Genuss des Fleisches von Thieren auftreten, die an septicämischen Processen eines puerperalen oder traumatischen Fiebers, an Enteritis oder Pneumoenteritis gelitten hatten. Wie schon mehrmals bewiesen ist, besteht die gastro-intestinale Form der Fleisehvergiftungen in einer Infection durch Mikroorganismen, dem Gärtner'schen Bacillus enteritidis sehr ähnlich. Diese Bakterie, oder wenigstens eine ihrer Varietäten, scheint uns identisch mit dem von Johne (3), Fischer (4), Poels u. Nolen (5), Holst (6), Flügge u. Känsche (7), Günther (8) und neuerdings von Silberschmidt (9) und G. Pouchet (10) im verdächtigen Fleische oder in den Organen der durch Genuss dieses Fleisches tödtlich erkrankten Personen gefundenen Bacillus. Im Jahre 1892 und 1895 haben wir in den Epidemieen von Moorseele und Gent diesen Mikroorganismus nachgewiesen und seine Beziehung zu gewissen Epizootien, wie Hog-Cholera und infectiöse Kälberpneumo-enteritis, betont (11).

Diese hier genannten gastro-intestinalen Erscheinungen alimentären Ursprunges haben nichts mit dem Botulismus zu thun; sie sind viel weniger gefährlich, viel häufiger und werden mit Erfolg durch Sanitätsmassregeln der Fleischbeschau bekämpft. 
Vergleichen wir jetzt die klinische Beschreibung des classsischen Botulismus, wie sie von mehreren Autoren Müller(11), Husemann (12), Böhm (13), Senckspiehl (14), etc. angegeben ist, mit dem in Ellezelles beobachteten Symptomencomplex, so geht daraus bestimmt hervor, dass kein wesentlicher Unterschied besteht zwischen dem in unseren Fällen durch Schinken hervorgerufenen und dem in Deutschland-Qesterreich durch einzelne Würste verursachten. Alle Hauptsymptome finden sich hier wie da, insbesondere die charakteristische externe und interne Ophthalmoplegie. Ausserdem rechnen wir zu dem Ellezelles'schen Krankheitsbild, wie zu dem eigentlichen Botulismus, motorische Störungen der Muskelgruppen im Gebiete der N. facialis, N. glosso-pharyngeus, N. hypoglossus, N. vagus u. s. พ́. Dysphagie bis Aphagie, Aphonie, croupartiges Husten, secretorische Stockung werden in beiden Erkrankungsformen erwähnt. Endlich sind noch hartnäckige Obstipation, grosse Muskelschwäche, fieberfreies Verhalten und Intactheit der psychischen Functionen beiden gemein.

Das zu Ellezelles beobachtete Syndrom umfasst, wenn es vollständig ist, ebenfalls die respiratorischen und circulatorischen Störungen, welche bei der Wurstvergittung constant beobachtet werden. Die Herzthätigkeit war in mehreren Fällen sehr herabgesetzt, Puls langsam, weich, Athmung erschwert, oberflächlich und beschleunigt. Es traten dyspnoische Anfälle auf, und es bestand eine Neigung zur Syncope. Der Exitus letalis zu Ellezelles, wie der der Wurstvergiftung, fand im Coma oder asphyctischen Collaps statt.

Der Verlauf der einzelnen Krankheitserscheinungen ist ebenfalls sehr ähnlich: gastrische oder gastro-enteritische Störungen treten zuerst auf; darauf folgen die optischen und dysphagischen Beschwerden. Die Accommodationslähmung, die Mydriasis dauerten mehrere Wochen.

Einigen Symptomen, welche von Husemann (16), Bohm (17) erwähnt sind und von den Aerzten zu Ellezelles nicht beobachtet wurden, können wir kein grosses Gewicht beilegen, so z. B. Blässe der Haut, Cyanose der Extremitäten, Unempfindlichkeit der Fingerspitzen, Mandelentzündung u. s. w. Diese Erscheinungen fehlen bisweilen in den typischen Fällen von Botulismus.

Ein Widerspruch besteht nur in einem Punkt: bei den Classikern wird das Vorhandensein von dickflüssigen Secreten, welche sich im Athmungsapparate sammeln, nicht angegeben. Im Gegentheil Trockenheit der Mundschleimheit und der Nase wird als constant angegeben. $\mathrm{Zu}$ Ellezelles wurde in allen schweren Fällen eine Hypersecretion in Mund und Rachen beobachtet; bei mehreren Leichterkrankten war sie nicht vorhanden, die Schleimhaut war ganz trocken, roth und ohne Spur von 
Mucusbelag. In unseren Thierversuchen andererseits waren abnormer, oft sehr ausgesprochener Speichelfluss und mucöse Absonderung fast constant, wie wir weiter unten erwähnen werden.

Diese Hypersecretion kennzeichnet demnach in gewissem Maasse die Fälle von Ellezelles, ist aber auch in einer anderen Schinkenvergiftung von Roth (18) beobachtet worden.

Der Botulismus kann also nicht nur durch einzelne Wurstarten, sondern auch durch Schinken hervorgerufen werden. Jedoch sind nur selten typische Fälle durch Schinkengenuss beobachtet worden, obwohl gerade der Schinken oft als Ursache alimentärer Erkrankungen angesehen wird. In der ganzen Litteratur haben wir nur die Beobachtungen von Roth (19), Uhlrich (20), Groenouw (21) und de Visscher (22) finden können.

Andere Lebensmittel, z. B. Conserven oder Büchsenfleisch haben ebenfalls ähnliche Frscheinungen zu Stande gebracht. Im Jahre 1878 hat du Mesnil (23) zu Lorient eine oft citirte Epidemie beschrieben. Veröffentlicht wurden noch Fälle von Botulismus nach Genuss conservirter Krickenten (24), Hasenpastete (25), Presskopf (26), Spickgans (27), geräucherten Fleisches (28) u. s. w.

Doch sind im Ganzen, ausser den eigentlichen Wurstvergiftungen, bis jetzt nur wenige gut charakterisirte Fälle von Botulismus publicirt worden. Wenn trotzdem wiederholentlich geäussert wird, dass der Botulismus ziemlich häufig durch den Genuss verschiedenartigster Fleischnahrung bedingt ist, so scheint dies nur daher zu kommen, dass die Symptomatologie der erwähnten Fälle nicht genügend berücksichtigt und mit der gewöhnlichen Form der gastro-intestinalen Fleischvergiftung verwechselt wird.

Nach dem Genuss von Fischen sind zuweilen Erkrankungen aufgetreten, welche von dem classischen Bild des Botulismus nicht unterschieden werden konnten. Cohn (29), Schreiber (30), Hirschfelt (31), Alexander (32) n. s. w. führten sehr beweisende Fälle an; neueren Untersuchungen jedoch seitens russischer Aerzte verdanken wir die jetzt festgestellte Thatsache, dass die häufigste Form des Ichthyosismus mit der Wurstvergiftung fast identisch ist. Um sich davon zu überzeugen, genügt es die Beobachtungen von v. Arrep (33), Arustamoff (34) und N. Sc hmidt (35) durchzulesen.

Endlich sind einige Autoren der Meinung, dass die botulinische Erkrankung ebenfalls mit gewissen, durch Mollusken, Muscheln, Austern u. s. w. hervorgerufenen Vergiftungen verwandt sind. Neuerdings hat Brosch (36) zu Wien einen rasch letal verlaufenen, durch 
Genuss von Austern bedingten Fall berichtet. Er behauptet mit Bestimmtheit, dass die Erscheinungen wesentlich die gleichen waren, wie sie bei Fisch- und Wurstvergiftungen beobachtet werden.

Es scheint in der That, das gewisse nervöse Symptome, unter anderen Pupillenerweiterung, nicht so selten sind in Folge des Genusses von schlechten Mollusken. Von den drei Hauptformen, unter welchen der Mytilismus sich äussert, nämlich der exanthematischen, der gastro-intestinalen und der paralytischen, kann jedoch nur die letztere in Betracht kommen (37). Des Weiteren sei noch bemerkt, dass in den sorgfältigst beobachteten Fällen, wie denjenigen von Wilhelmshafen, welche 1885 und 1887 viel Aufsehen erregten, mehrere der charakteristischen Symptome des Botulismus vermisst werden und dass im Gegentheil Erscheinungen, die diesen Epidemieen eine besonderes Bild darboten, vorhanden waren.

In den Fällen von Wilhelmshafen trat der Tod meistens schon nach einigen Stunden auf, während die intensiven Vergiftungserscheinungen sich bereits eine viertel bis eine halbe Stunde nach dem Genuss äusserten. Uebrigens nimmt die Krankheit für gewöhnlich einen acuten Verlauf, auch werden nicht bei den in Heilung übergehenden Fällen, wie beim Botulismus, wochenlange Sehstörungen beobachtet.

Die Läsionen dieser Form der Miesmuschelvergiftung, welche so genau von Pathologen wie Virchow (38), Wolff (39) u. s. w. studirt worden sind, können ebenfalls als Unterscheidungsmerkmale gelten.

Endlich widèrsteht das Gift der Wilhelmshafener Miesmuscheln sicherlich höheren Temperaturen; denn die gekochten, ebenso wie die rohen und lebendigen Muscheln, und selbst das Wasser, in welchem sie gekocht wurden, wirken sehr toxisch nicht nur beim Menschen, sondern auch bei Fütterungsversuchen bei verschiedenen Thierspecies wie Hund, Katze, Huhn u. s. w. Man weiss nun, dass Würste, Schinken, eingesalzene Fische durch Kochen absolut unschädlich gemacht werden (40) und dass diese verdächtigen Nahrungsmittel fast niemals Zeichen von Vergiftung bei Hunden, Katzen, Hühnern hervorrufen. Unsere mit dem Ellezelles'schen Schinken angestellten Untersuchungen bestätigen vollkommen diese schon längst bekannte Thatsache. Das Gift dieses Fleisches wird ebenfalls für die empfängliche Thierspecies unwirksan, wenn es während einer Stunde auf $70^{\circ}$ erwärmt wird; niemals hat es die geringste Störung beim Hunde oder bei Hühnern per os hervorgerufen.

Die hervorgehobenen Unterschiede rechtfertigen deshalb den Schluss, dass die schwerste Form des Mytilismus eine eigenartige Vergiftung vorstellt. Unbegründet ist es jedenfalls, den foudroyanten Verlauf, die klinischen und anatomischen Besonderheiten durch eine höhere Wirksamkeit oder Concentration des Giftes erklären zu wollen. 
Der in mebrfacher Hinsicht so interessante Fall von Brosch scheint uns dem echten Botulismus, speciell den Erkrankungen zu Ellezelles, bei Weitem ähnlicher zu sein. Affen, welchen wir den Schinken zu essen gaben, verendeten in wenigen Stunden; das Krankheitsbild zeigte die grösste Uebereinstimmung mit eitirter Austernvergiftung.

Kurz skizzirt besteht das Syndrom des Botulismus, gleichwohl ob es durch Genuss von Wurst, Schinken, Conserven, Fischen u.s.w. hervorgerufen wird, wesentlich aus einem neuro-paralytischen Symptomencomplex: Secretionsstörungen und symmetrische motorische Lähmung, total oder partiell, welche sehr wahrscheinlich in Läsionen des Centralnervensystems ihren Sitz haben. Der Botulismus charakterisirt sich also:

1. Durch eine Ab- oder Zunahme der Speichel- und Schleimabsonderung des Mundes, Rachens u. s. w.

2. Eine mehr oder weniger ausgesprochene externe und interne Ophthalmoplegie (Blepharoptosis, Mydriasis, Accommodationslähmung, Diplopie, Strabismus int.).

3. Dysphagie bis Aphagie, Aphonie, hartnäckige Obstipation, Urinretention:

4. Fehlen von Fieber, von Sensibilitäts- und Gehirnstörungen.

5. Diesem Symptomencomplex schliessen sich oft Athmungs- und Herzstörungen an, welche mehr oder weniger schnell unter den Erscheinungen der Bulbärparalyse zum Tode führen können.

6. Endlich treten die charakteristischen Symptome (Mydriasis, Ptosis u. s. w.) am frühesten 12 bis 24 Stunden nach dem Genuss der verdächtigen Nahrungsmittel auf. Oft sind sie ron vorübergehenden gastro-intestinalen Erscheinungen eingeleitet; sie entwickeln sich allmählich und verschwinden erst nach Wochen.

Das bereits zur Genüge bekannte Krankheitsbild scheint uns auf sicherer Basis zu beruhen. Mit Ausnahme kleiner Abweichungen wurden die angeführten Symptome in der weitaus grösseren Zahl der Fälle beobachtet. Uebrigens ist es leicht zu diagnosticiren und stellt einen wohl charakterisirten Symptomencomplex dar. Beim Fehlen der Anamnese könnte es nur mit gewissen, von den Neuro-Pathologen und Ophthalmologen studirten Erkrankungen; wie der asthenischen Bulbärparalyse (Erb'sches Syndrom), Polio-encephalomyelitis subacuta, gewissen 0 phthalmoplegieen u. s. w. verwechselt werden.

Bisher wurde die unverkennbare Aehnlichkeit dieser verschiedenen Krankheiten mit dem Botulismus noch nicht hervorgehoben. Um so mehr ist es jetzt angezeigt, da man in neuerer Zeit geneigt ist, das Erb'sche Krankheitsbild wie andere localisirten Erkrankungen des Central- 
nervensystems, den durch Bakterientoxine hervorgerufenen Läsionen der Nervenzellen zuzuschreiben. ${ }^{1}$

Alle Autoren stimmen darin überein, dass besondere organische Verānderungen, welche dem Botulismus eigen sein sollen oder wenigstens den tödtlichen Verlauf erklären könnten, total fehlen. Als Obductionsbefund wird im Allgemeinen, trotz sorgfältigster Beobachtungen, nur eine geringe Hyperämie der meisten Organe, besonders der Hirnhăute, der Bronchien, der Lungen, des Darms, der Leber und der Nieren erwähnt. Diese Hyperämie, die von den meisten Autoren erwähnt wird, erklärt sich sehr leicht durch die Herzschwäche und Dyspnoë, welche im letzten Stadium der Krankheit immer auftreten.

Von Seite des Magens und des Dünndarms besonders hat man ziemlich oft Spuren einer localen Wirkung des vermuthlichen Giftes gefunden; ausser der Hyperämie werden noch Lockerung der Schleimhaut, Erosionen und wenig ausgebreitete Geschwüre erwähnt.

Bis jetzt hat man diese makroskopischen Aenderungen noch nicht mikroskopisch untersucht. Die einzigen Beobachtungen, welche wir benutzen könnten, sind die von Souchay (41). In drei Fällen sind einzelne Organe, Nieren, Leber, Milz a. s. W., die von gerichtlichen Sectionen herrührten, studirt worden. Eine systematische Untersuchung aller Organe mittels der verschiedenen Methoden der heutigen Technik fehlt und die histo-pathologische Untersuchung des centralen und peripherischen Nervensystems ist nicht berücksichtigt worden.

Souchay giebt an, dass entzündliche Veränderungen im Magen xund Darmcanal durchaus fehlen. Ausser der passiven Congestion des Darmes, der Lungen, des Gehirns und der Nieren, hat er nur in einem Fall interstitielle Hepatitis gefunden. Parenchymatöse, fettige Degeneration der Leber, der Nieren u. s. w., welche so häufig bei toxischen oder septischen Erkrankungen vorkommt, wird nicht angegeben.

Die Obduction der zwei zu Ellezelles Verstorbenen bewies das Vorhandensein von intensiven Läsionen des Gastro-Intestinaltractus, welche bei Wurstrergiftungen $u$. s. w. nur selten beobachtet worden sind. Es ist wirklich schwer anzunehmen, dass die Erweichung und äusserste Brüchigkeit der Magenwände bei Obductionen, die spätestens 24 Stunden nach dem Tode stattfanden, ausschliesslich als cadaveröse Processe anzusehen sind. Wir nehmen eher das Vorhandensein eines localen, inten-

${ }^{1}$ In Oesterreich, Herzegowina u. s. w. sollen Vergiftungen durch essbare Pilze sehr häufig sein, welche den Wurst-, Fisch- und Fleischvergiftungen ähnlich sind, wie mir Karlinski berichtete und Weiss in der Gesellschaft der Aerzte zu Wien nenerdings vorgetragen hat. Vgl. Weiss, Ueber Pilzvergiftung. Wiener med. Wochenschrift. 3. April 1897. 
siven entzündlichen Infiltrationsprocesses an. Uebrigens wurde diese Ansicht durch die Ergebnisse unserer Thierexperimente gestützt. Bei Meerschweinchen, Kaninchen u. s. w., die Proben des verdächtigen Schinkens zu essen bekamen, traten deutliche Veränderungen im Magen auf, welche sich in Form von Entzündung bis Nekrose äusserten.

Andererseits wiesen Leber und vielleicht Nieren eine fettige Degeneration toxischer Natur auf. Aehnliche Iaäsionen wurden regelmässig constatirt bei den Thierexperimenten mit Schinken und Culturen des aus diesem Fleische isolirten Mikroorganismus.

Die Untersuchungen von Souchay und die unsrigen stimmen in dem Punkt überein, dass im Innern der menschlichen Organe specifische Bakterien nicht nachzuweisen waren. Es bedarf einer volikommneren Untersuchungsmethode, als der mikroskopischen, um die specifischen Bacillen, welche sich nur sehr spärlich in den Organen vorfinden können, aufzufinden. Wie schon gèsagt, glückte uns die Cultur.

Die durch den Ichthyosismus in Russland hervorgerufenen Veränderungen der Organe sind ebenso wenig charakteristisch und constant wie diejenigen des Botulismus. Schreiber (42) beobachtete nur eine Lungeninfiltration oder Schluckpneumonie, v. Anrep (43) eine merkliche venöse Hyperämie der Hirnhäute, des Gehirns, der Lungen, der Nieren, der Leber u. s. w. Alle diese Läsionen hält Arustam off für asphyctischen Ursprunges.

Mikroskopisch wurden die Organe und das Nervensystem bei Fischvergiftung noch nicht untersucht. Nur Schreiber gibt’einige Auskünfte darüber. Er hat keinerlei Läsionen an den Schnitten des Bulbus, Medulla, N. oculomotorius, N. giosso-pharyngeus constatiren können.

Die ganze pathologische Anatomie des Botulismus, des Ichthyosismus ist also bis jetzt fast gänzlich unbekannt; jedenfalls muss sie mittels der in den letzten Jahren vervollkommneten Methoden der Histologie und Neuro-Pathologie wieder aufgenommen werden. Leider haben die Fälle von Ellezelles wenig zur Lösung dieser Fragen beigetragen, da die einzelnen Organe einer Lejche nicht zu einer gründlichen Untersuchung verwendet werden konnten. Um diese Lücke in der Pathogenese auszufüllen, haben wir die Organe von mehreren, mit dem verdächtigen Schinken und Culturproducten behandelten Thieren einer systematischen histologischen Untersuchung unterzogen.

Ueber das vermuthliche Gift des Botulismus sind bereits viele Hypothesen gemacht worden. Nachdem dasselbe vergebens unter den verschiedensten unorganischen und organischen Substanzen gesucht wurde, sah man sich schliesslich dazu veranlasst, es als eine Fäulnissbase, wie 
schon Schlossberger (44) 1852 für das Wurstgift annahm, anzusehen. Jedoch ist bis heute das Gift noch nicht entdeckt worden.

Die Ptomaïne, wie Cholin, Neuridin u. s. w., welche Ehrenberg (45) aus einer Wurst isolirt hat, sind sehr wenig giftig. Das Misslingen der ausgeführten Analyse versuchte man dadurch zu erklären, dass die Fleischwaaren sich stets in einem zu weit vorgeschrittenen Fäulnisszustand befanden. Wie Brieger nachgewiesen hat, verwandeln sich die böchst toxischen Ptomaïne, welche sich im Anfang der Eiweissfäulniss bilden, in einfachere, wenig oder nư bei grösseren Mengen giftige Verbindungen um.

Die Vermuthung, dass durch die gewöhnliche Eiweissfäulniss das Gift des Botulismus gebildet werde, stiess kaum auf Widerspruch. Man hat ganz besonders das Neurin oder ähnliche Basen als wirksames Agens verschiedener Fleischvergiftungen in Frage gestellt.

Jedoch rufen die Ptomaine der Neurinreihe bei den Thieren das Bild des Botulismus keineswegs hervor. Die Erscheinungen stimmen vielmehr eher mit denen der Muscarinvergiftung überein, die Curarewirkung z. B. ist noch viel ausgesprochener. Bei der Katze, welche wir als das geeignetste Versuchsthier betrachten, beobachtet man sehr oft eine Pupillenverengerung anstatt Erweiterung, welche regelmässig bei dem Experimente mit dem Ellezelle'schen Schinken sich einstellt, ausserdem blutige Entleerungen, unwillkürlichen Harn- und Spermafluss, clownische Zuckungen, alles dem Botulismus fernstehende und nie bei unseren Thieren beobachtete Symptome: Andererseits werden gewisse limitirte Paresieen, wie Zungenprolaps u. s. w., bei der Neurinvergiftung nicht erwähnt.

Die Aehnlichkeit des Krankheitsbildes des Botulismus mit dem des Ichthyosismus sollte vermuthen lassen, dass unter den Ptomaïnen der Fischfäulniss sich welche finden, deren Wirkung mehr der Wurstvergiftung gleicht. In der That ruft Aethylidendiamin, in verdorbenem Kabeljau durch Brieger (46) entdeckt, neben Neuridin und Muscarin, bei Meerschweinchen, Mäusen, Kaninchen ausgesprochene Pupillenerweiterung, Speichelfluss, Dyspnoe und Muskelschwäche hervor. Leider sind die Frscheinungen der Vergiftung bei der Katze unbekannt.

Das Gadinin, das Methylguanidin und noch andere Basen aus verfaulten Fischen könnte man auch in Betracht ziehen. So ist Bisch of †47) der Meinung, dass flüchtige Basen der Methyl- und Aethylaminreihe bei den von Hirschfeld beobachteten Fällen mitgewirkt haben.

Doch scheint keines der Fäulnissalkaloide als das eigentliche Gift des Botulismus angesehen werden zu können. Die Veränderungen, welche Würsten, Fischen u. s. w. ihre fürchterliche Wirkung verdanken, haben nichts mit der gewöhnlichen Fäulniss gemein. Es ist eine feststehende 
Thatsache, dass Nahrungsmittel ohne jede Spur von Fäulniss die heftigsten und charakteristischen Erscheinungen hervorrufen könmen.

Die Frage über die Natur des botulinischen Giftes glaubte man endlich durch die Entdeckung einer Base gelöst zu haben, welche v. Anrep aus giftigem Störfleisch erhielt und die sich auch in dem Magen-Darminhalt, in den Organen und dem Harn der Verstorbenen nachweisen liess.

Die physiologische Wirkung dieses Ptomainns auf Thiere soll, nach v. A nrep, ,eine vollkommene Wiederholung des Symptomencomplexes sein, welchen die Opfer der Fischvergiftung darboten" (48).

Uns scheint jedoch der Parallelismus zwischen der experimentellen Vergiftung durch sogenanntes „Ptomatropin“ (49) v. Anrep's und dem Symptomencomplex des Ichthyosismus s. Botulismus beim Menschen sehr mangelhaft zu sein. Neben gewissen oberflächlichen Analogien sind die Abweichungen zahlreich. v. Anrep's Ptomaïn wirkt auf Hunde, Fröscbe u.s.w. mehr oder weniger atropinartig, doch bleiben die eigenthümlichen Lähmungen bei diesen Thieren wie bei der Katze aus.

Der thatsächliche ätiologische Zusammenhang zwischen den Erscheinungen bei den Kranken und den Wirkungen des dargestellten Giftes ist nicht klargestellt, da die directe Wirkung des verdächtigen Störfleisches auf die Thiere vernachlässigt wurde. Sonst hätte sich gezeigt, dass man Hunden, Fröschen u. s. w. grosse Mengen dieses Fleisches darreichen kann, ohne ihren Gesundheitszustand irgendwie zu beeinflussen.

Da das Gift nur bakteriellen Ursprunges sein kann, drängt sich die Frage auf, welchem Mikroorganismus die Nahrungsmittel die schädlichen Noxen verdanken. Bis heute hat man sich ohne Erfolg bemüht, den betreffenden Mikroorganismus aufzufinden. Seit den mit unvollkommenen Mitteln angestellten Untersuchungen von Hoppe-Seyler, Virchow, Eichenberg (50) und mehreren Anderen, haben nur drei Forscher die neueren Culturmethoden zur Isolirung der vermuthlichen Bakterien des Botulismus angewandt.

Nauwerck (5̄1) züchtete aus einer Wurst unter anderen Bakterien einen Bacillus, dessen pathogene Wirkung überhaupt nichts Specifisches zeigte, und der wohl als eine gewöhnlicbe harmlose Bakterie (B. mesentericus) angesehen werden kann (52).

Nach v. Anrep und N. Schmidt wird das Fischgift höchstwahrscheinlich von Mikroorganismen producirt, die den Fisch selbst inficiren. Dennoch fand Wyssokowitz (53) im Darmkanal eines der Verstorbenen, die chemische Untersuchung wurde von v. Anrep vorgenommen, eine grosse Anzahl von Oedem-Bacillen.

Im Jahre 1891 giebt Arustamoff (54) in einer vorläufigen Mittheilung an, dass es ihm gelungen sei, aus mehreren gesalzenen Fischen, 
deren Genuss heftige botulinische Erscheinungen hervorgerufen hatte, einen besonderen Mikroorganismus zu isoliren. Derselbe war ebenfalls in den menschlichen Organen, Leber, Milz, Nieren u. s. w. sehr verbreitet. Seine culturellen Merkmale haben mit denen der wohlbekannten Colibacillen die grösste Aehnlichkeit. Jedenfalls erlaubt die Pathogenität des Arustamoff'schen Mikroorganismus keineswegs den Schluss, ihn als Erreger der durch die verdächtigen Fische beim Menschen hervorgerufenen Erkrankung hinzustellen.

Während wir die bakteriologische Untersuchung des uns zugeschickten Materials anstellten, schien es uns zweckmässig, nachzusehen, ob das Verabreichen des Schinkens charakteristische Symptome im Thierexperiment zu bewirken im Stande war. Wenn es sich herausstellte, dass die verschiedenen Laboratoriums-Thierarten unempfänglich wären und das physiologische Reagens, so zu sagen, vollständig fehlen würde, so würde das Isoliren eines specifischen Giftes ziemlich aussichtslos gewesen sein.

Glücklicher Weise sind nicht alle Thierarten, wie allgemein angenommen wird, gegen die Giftwirkung refractär. Der Schinken ruft bei gewissen Thieren ein Krankheitsbild hervor, welches uns für das Studium der Pathogenität des aus diesem Fleische gewonnenen Anaëroben-Mikroorganismus eine feste Basis gegeben hat.

Unsere Untersuchungen wurden ohne vorgefasste Meinung über die Natur des botulinischen Agens sowie über den Mechanismus der sehr charakteristischen Wirkung angestellt, welche er auf mehrere Thierspecies ausübt.

II.

Seit langer Zeit haben sich verschiedene Forscher bemüht, Thiere durch Verfütterung von Nahrungsmitteln wie Würsten, Fischen, Schinken, welche beim Menschen tödtliche botulinische Erscheinungen hervorgerufen hatten, zu inficiren. Unter Anderen geben Kerner, Weiss, Jäger, Schlossberger, Springer an, dass der Genuss derartig schädlicher Nahrungsmittel bei Hund, Katze, Schwein u. s. w. ohne jede Wirkung ist.

In neuerer Zeit sind Müller, Pürckhauer (55), Nauwerck, Kaatzer(56), u.s.w. zu derselben Ueberzeugung gelangt. Nur Groenouw erwähnt ganz kurz einige Versuche, die im Flügge'schen Laboratorium mit verdächtigem Schinken angestellt worden sind. Bitter gab weissen Mäusen Fleischstückchen zu fressen; die Thiere starben ohne Ausnahme 
innerhalb 24 Stunden unter den Erscheinungen eines Darmkatarrhs. Mit einzelnen Organen derselben wurden wiederum Mäuse gefüttert, welche gesund blieben. Aus diesem Versuch würde man, nach Bitter, schliessen müssen, dass ,das in dem Sehinken enthaltene Gift aus Ptomaïnen bestand, nicht aus Mikroorganismen, da es sich nicht in den ersten Mäusen erschöpft haben würde". Weder in den Geweben der verstorbenen Thiere, noch in dem Schinken liess sich durch die üblichen Methoden (ärobe Plattencultur ?) eine besondere Bakterienart nachweisen (57).

N. Schmidt, Casselmann (58) und früher noch zahlreiche russische Autoren haben ebenfalls Katzen mit sehr giftigen eingesalzenen Fischen gefüttert und stets negative Resultate erhalten. Nur einmal beobachtete N. Schmidt intensive Krampfanfälle und in einigen Stunden den Tod nach Verabreichung von 300 grm Störfleisch.

Man ist deshalb geneigt, mit Brieger anzunehmen, dass die den Botulismus und den Ichthyosismus hervorrufenden Gifte sich für Thiere, wie Schwein, Huhn, Katze und Hund unsehädlich erweisen, und man glaubte bis jetzt, dass ,die Theorie der Wurstvergiftung sich einer texperimentellen Kritik entzieht, insofern als die Verfütterung der Würste an Thiere keine Erkrankung hervorruft; da, wo vermuthlich giftige Würste Thiere afficirten, handelte es sich offenbar um Trichinose, und man ist vielleicht berechtigt, in dem negativen Ausfalle der Thierversuche ein differentiell diagnostisches Merkmal gegenüber der Infection durch trichinöses oder milzbrandkrankes Fleisch zu erblicken“ (59).

Trotz der wenig ermuthigenden Erfahrungen unserer Vorgänger haben wir die Hoffnung nicht aufgegeben, aus den Experimenten in anima vili einige interessante Daten zu gewinnen.

Wir haben den Schinken theilweise als solchen, theilweise als wässerigen Extract oder als Maceration eingegeben. Der kalte Aufguss hatte den Vortheil, ein Product von mittelmässiger, constanter Wirksamkeit zu liefern für den Fall, dass die Krankheitserreger ungleichmässig im Fleische vertheilt seien. Die Maceration wurde in der Art bereitet, dass ein Stück Fleisch, Muskel und Fett ungefähr zu gleichen Theilen, in einem ausgeglühten Mörser mit 5 Theilen sterilisirten Wassers zerrieben wurde. Wir haben ausserdem versucht normalen Nahrungsmitteln, wie gekochtes Schweinefleisch, Bouillon u. s. w. die besondere Wirksamkeit des Schinkens mitzutheilen, indem wir diese Producte mit Schinkenpartikelchin oder einigen Tropfen der Maceration zur Aussaat einbrachten. A priori war schon anzunehmen, dass es nicht sicher gelingen würde, durch diesen Versuch neues künstliches Material für weitere Experimente zu gewinnen. Nichtsdestoweniger sind die unter verschiedenen Bedingungen, wie Anaërobiose, u. s. w. angestellten Versuche gelungen. 
Auf diese Weise präparirte Nahrungsmittel zeigten sich sehr activ und haben uns in den Stand gesetzt, die Lücken der mit dem Schinken angestellten Fütterungsversuche glücklichst auszufüllen.

I. Ingestion. Vier Mäusen wurden kleine Stückchen Schinkenfleisches, ungefähr $2-3 \mathrm{grm}$, verfüttert. Sämmtliche Thiere erkrankten nach 48 Stunden. Sie sassen beweglos da-mit gesträubten Haaren, krummem Rücken, kleinen, theils verklebten Augen, ohne Fresslust zu zeigen. Die Bewegungen waren erschwert, sie krochen auf dem Bauch dahin, die gespreizten Hinterglieder nach sich ziehend. Sie starben endlich in zusammengekauerter Lage, die Extremitäten von sich gestreckt, ohne jegliche Krampfbewegung. Bei der Obduction fand man nur ausgesprochene Hyperämie der Brust- und Bauchorgane.

Die todten Mäuse wurden vier weiteren Mäusen verfüttert; sie hatten schnell die Weichtheile, Eingeweide, Leber u.s.w. verzehrt, blieben aber alle am Leben.

Vier weisse Ratten wurden drei Tage lang mit Schinken gefüttert, keines der Thiere erkrankte.

Zwei junge Katzen bekamen nach 18stündiger Hungerpause je 20 grm Fleisch, Muskeln und Speck. Acht Stunden später erhielten sie noch mit 25 cem Maceration durchtränktes Brod. Nach 24 Stunden verzehrten beide noch Milch, der $50 \mathrm{~cm}$ Maceration beigemengt war. Sie erkrankten nicht schwer. Die eine zeigte Mattigkeit, wenig Appetit; die Augen thränten, es bestand Coryza und ein continuirlicher Husten. Am folgenden Tag wurde die Stimme heiser. Das Thier hörte jedoch nicht auf, Nahrung zu sich zu nehmen; Pupillenerweiterung war wenig ausgesprochen und nur temporär. Nach drei Wochen erholte sich das 'Thier vollständig.

Das zweite Thier blieb während einiger Tage matt und appetitlos und zeigte keine besonderen Erkrankungssymptome.

Zwei kräftige und seit dem vorhergehenden Abend hungernde Meerschweinchen wurden mittels Schlundsonde mit 10 eem frisch bereiteter Maceration gefüttert. Ein drittes erhielt auf dieselbe Weise $5 \mathrm{ccm}$, ein viertes $2 \mathrm{ccm}$. Nach wenigen Stunden waren sie alle äusserst schwer erkrankt: bewegungslos liegen sie auf dem Bauch, die Glieder breit auseinander gestreckt, die ganze Musculatur schlaff und leblos. Die Respiration war ängstlich, durch Erstickungsanfälle unterbrochen, Temperatur fiel bis $3^{\circ}$ herab. Pupillen erweitert ohne Reaction. Eine helle, dünne Flüssigkeit benetzte Nase und Maul.

Nach 12 bis 48 Stunden wurden sămmtliche Meerschweinchen todt gefunden. Zwei weitere Thiere, mit $1^{\mathrm{ccm}}$ und $0.5 \mathrm{~cm}$ Maceration behandelt, blieben am Leben. 
Bei der Autopsie wurden fast identische Läsionen gefunden: Dünndarm, wie Leber und Nieren sehr hyperämisch; Milz klein, nicht cyanotisch; Lungen compact, wenig lufthaltig, dunkelroth mit breiten schwarzen Infarcten; Harn- und Gallenblase prall gefüllt. Der Magen ist mit einer grauen Flüssigkeit prall gefüllt. An einigen Stellen ist die Wand hellroth, in Folge von Gefässinjection. Die Mucosa ist weich, grau und leicht zerreissbar.

Einführung von 10 eem Maceration beim Kaninchen blieb erfolglos. Ein Thier, welches mit $20 \mathrm{ccm}$ Maceration durchtränktes Brod frass, starb nach 48 Stunden, nachdem es dieselben Erscheinungen wie die Meerschweinchen gezeigt hatte. Dosen von 10 und $5{ }^{\mathrm{ccm}}$ erzielten nur Mattigkeit, Mangel an Fresslust und Abmagerung.

Beim Affen rief die Einführung von $10^{\mathrm{cem}}$ und $5^{\mathrm{cm}}$ in den Magen sehr acute Krankheitssymptome und den Tod in wenigen Stunden hervor. Ein kleiner Rhesus, von 2800 grm Gewicht, welcher mit $5^{\mathrm{ccm}}$ des Mittags gefüttert wurde, erkrankte am folgenden Nachmittag sehr schwer. Ein dritter bekam nur $2 \mathrm{~cm}$. Beide Thiere verendeten in 24 bis 30 Stunden.

Der Affe, dem wir die kleinste Dosis gaben, war schon innerhalb 12 Stunden krank. Am Mittag stellte sich grosse Unruhe ein, das Gesicht färbte sich röthlich, die Augen wurden glänzend, thränend, hingegen blieben die Pupillen normal. Der Puls und die Athmung sind etwas beschleunigt. Das Thier hustet und niesst öfters. - Gegen 4 Uhr ist der Zustand noch derselbe. Dickflüssiger Schleim sammelt sich in Nase und Mund und verursacht Erstickungsanfälle. Die Pupillen sind augenscheinlich erweitert und reagiren nur träge auf Lichteinfall. Trotz Andauer des Reizes vergrössern sie sich wieder. Das Thier ist willenlos, reagirt wenig und sitzt zusammengekauert in einer Ecke seines Käfigs. Es unterscheidet wohl die ihm bekannten Personen und antwortet auf ihren Ruf, doch zeigt es durchaus keine Lust, sich von seinem Platze fortzubewegen. Es isst noch einige Leckerbissen und verschluckt Milch ohne jegliche Mühe. - Gegen 7 Uhr Abends verändert sich sein $\mathrm{Zu}$ stand plötzlich. Es ist vollständig unbeweglich und gleichgültig gegen alles, sitzt zusammengekauert da und lässt den Kopf zwischen seine Beine fallen. Athmung wird schnaubend, unregelmässig, Puls sehr schwach und rerlangsamt. Der Gesichtsausdruck ist starr, die Augen, mit aussergewöhnlich erweiterten Pupillen, sind halb bedeckt durch die bewegungslosen Augenlider. - Das Thier verschied in den ersten Nachtstunden. (Vgl. Taf. II, Fig. 2.)

Die Veränderungen der Organe waren ziemlich stark ausgesprochen. Stellenweise zeigte die Haut blutrothe Flecke. Der Magen war ein wenig erweitert, die Schleimhaut sehr congestionirt; Lungenbasen splenisirt; Milz 
und Nieren zeigten nichts Abnormes; Hirnhäute hyperämisch, Arachnoïdea mit deutlichen Blutherden bedeckt; kleine diffuse Hämorrhagieen finden sich im Gehirn- und der Medulla.

2. Subcutane Injection. - Sehr kleine Dosen Maceration, weniger als $0.001 \mathrm{~cm}$ tödten in 24 Stunden weisse Mäuse von 15 bis $20 \mathrm{grm}$ Gewicht unter paretischen Erscheinungen ähnlich denen, welche durch Ingestion hervorgerufen werden.

Die Ratten sterben nur nach Einspritzung höherer Dosen unter denselben Symptomen.

Hunde und Hühner sind fast refractär. Bei Injection von $10 \mathrm{~cm}$, die 3 Tage nach einander wiederbolt wurde, zeigte ein Hund Fieber, Mattigkeit, Abmagerung und starb nach einer Woche ohne weitere Erscheinungen. Der Tod war durch sehr intensive Entzündung und Eiterung des subcutanen Gewebes bewirkt. - 20 bis $30 \mathrm{cem}$ sind bei 2 Hühnern ohne besondere Wirkung geblieben.

Bei Tauben, welche eine Dose von 1 bis $2^{\text {ecm }}$ erhielten, sah man eine Reihe eigenartiger Störungen sich entwickeln, welche zum Tode führten. Nach 36 bis 48 Stunden, verschiedene Male noch später, stellten sich die ersten Krankheitssymptome ein. Das Thier lässt die Flügel hängen; wenn man es greifen will, versucht es vergebens wegzufliegen. Die Fügel schlagen schwach und erfolglos; es bewegt sich kriechend mit ausgebreiteten Flügeln. Bald erhebt es sich nicht mehr; die Parese nimmt zu und bald tritt vollständige Lähmung ein. Der Kopf hängt bewegungslos herab und fällt zurück, wenn man ihn aufhebt. Es scheint sich auf dem Boden mittels seines Schnabels zu stützen. Die Federn sträuben sich und das Thier verbleibt während ganzer Tage regungslos in dieser charakteristischen Stellung. Zur selben Zeit sind auch gewöhnlich die Augenlider geschlossen, die Pupillen erweitert, ohne Reaction und nicht selten ungleichmässig beiderseits vergrössert. (Vgl.Taf.III, Fig. 2.) Alle Tauben ohne Ausnahme waren in den letzten Stunden von Schluckkrämpfen befallen, als ob sie versucht hätten, zu erbrechen; aus dem Schnabel floss eine grünliche, bisweilen reichliche Flüssigkeit.

Dieser krankhafte Zustand dauerte bei starken Dosen 6 bis 12 Stunden, oft 3 und sogar 4 Tage lang.

Endlich sterben die Thiere in der oben skizzirten Haltung mit halbgeöffneten Flügeln, gesenktem oder auf die Seite gefallenem Kopf und geschlossenen Augen.

Bei der Section findet man keine bedeutenden Veränderungen der Organe, ausser einem hyperämischen Zustand. Locale Läsionen sind nicht vorhanden. 
Bei Katzen, welche ohne Nachtheil ungeheure Dosen von dem für mehrere Thierarten höchst gefährlichen Fleisehe aufnehmen können, rufen Hauteinspritzungen der Maceration, bei verhältnissmässig geringen Quantitäten, ernstliche Erscheinungen und den Tod hervor.

Bei diesen Thieren beobachteten wir einen sehr eigenthümlichen Symptomencomplex und interessante Paresien einzelner Muskelgruppen.

Der krankhafte Zustand der Katze zeigt sich in einer Gestalt, wie wir ihn vorher niemals wabrgenommen hatten, und entspricht keiner der bisher bekannten und beschriebenen Vergiftung oder Infection.

Grosse Dosen, von 10 bis $5^{\mathrm{ccm}}$ pro Kilo, haben intensive Erseheinungen hervorgerufen ähnlich denen, welche bei Affen nach Verfütterung aufgetreten sind.

Bei einer mässigen Dose von 1 cem stellt sich nach verschiedenen Zeitabschnitten bei sämmtlichen Thiere der Tod ein, dem ein fast unveränderlicher Symptomencomplex vorausgeht. Nur zwei verstarben nach 48 bis 56 Stunden, sie waren sehr jung und athreptisch. Die anderen lebten durchschnittlich 9 Tage; ein einziges brachte es zu 26 Tagen.

Nach einem Latenzstadium von 24 Stunden, nicht selten erst nach 36 Stunden, während welchen die Katze ganz normal aussjeht, treten die ersten Krankheitserscheinungen auf. Die Thiere sitzen ruhig ohne ihre gewöhnliche Lebhaftigkeit und Heiterkeit da. Sie bewegen sich fast nicht mehr, verweigern jegliche Nahrung und erscheinen fortwährend wie eingeschlafen. Milch wird getrunken, aber ohne Gierigkeit. Weder Erbrechen noch Durchfall kommt vor.

Am Ende des 2. bis 3. Tages sieht man alsdann die eigenthümlichen Paresen auftreten. Das Aussehen des Thieres erlangt etwas Charakteristisches: sein Gesicht hat einen stumpfsinnigen Ausdruck; das bekannte Augenblinzeln und die Leckbewegungen bleiben aus. Die Bulbi sind fast bewegungslos, der Blick starr, atonisch, die Pupille ist erweitert und träge auf Lichtreiz. Die spontane Contraction der Iris scheint auch sehr eingeschränkt.

Dem Fortschritt der Erkrankung entsprechend wird die Mydriasis mehr und mehr bemerkbar, und zu gleicher Zeit accentuirt sich die Unempfindlichkeit auf Lichteinfall. Wenn im Anfang dieses Stadiums ein intensives Licht sich dem im Dunkeln gehaltenen Thiere plötzlich nähert, so zieht sich die Iris noch zusammen, aber stets nur langsam und ohne eine schlitzförmige Oeffnung anzunehmen, wie es bei der normalen Katze der Fall ist. Später, in den letzten Tagen, wird die Erweiterung ausserordentlich gross, der Rand beschränkt sich auf $1 \mathrm{~mm}$ und bleibt vollständig unbeweglich, selbst unter den kräftigsten Erregungen. Der Blick ist alsdann gläsern, absolut starr und giebt dem Gesicht einen sehr eigen- 
thümlichen Ausdruck. Die Iris ist gleichmässig retrahirt, so dass die Pupille ihre gewöhnliche runde Form darbietet.

Um uns vollkommen von der Ausdehnung der Irisstörung Rechenschaft zu geben, haben wir die Versuchsthiere stets mit gesunden verglichen, welche denselben Beleuchtungsbedingungen ausgesetzt waren.

Mit diesen Sehstörungen tritt zu gleicher Zeit ein Phänomen auf, welches unsere besondere Aufmerksamkeit erregt hat, und ohne Ausnahme bei allen unseren Katzen zu sehen war. Die Zunge tritt aus der Schnauze, sie hängt mehr und mehr heraus und bleibt bald ganze Tage lang prolabirt bis zu einer Länge ron 2 bis $3 \mathrm{~cm}$. Dieser Prolaps kann 8 bis 10 Tage dauern. Anfangs besitzt das Thier noch das Vermögen, die Zunge zurückzuziehen und für einige Zeit in normaler Stellung zu halten; es besteht eine unvollständige Lähmung. Später zieht es die Zunge nur mühsam auf Reize zurück, aber es streckt sie bald wieder hervor. Die Zunge wird trocken und faltig, zuweilen zeigt sie tiefe Einrisse in Folge Bisses der Nagezähne und des Zusammenziehens des Kiefers.

Zur selben Zeit, vom dritten Tage an, haben die Absonderungen aus Nase und Maul vollständig ihren Charakter verändert: graulicher, dickflüssiger Schleim häuft sich im Schlunde an und belästigt die Athmung in hohem Grade. Das Thier bekommt starke Würganfälle, um sich davon zu befreien. Von Zeit zu Zeit scheint es von Erstickungsanfällen bedroht. Es überkommt das Thier ein heiserer croupähnlicher Husten, welcher zu einer vorübergehenden Erleichterung führt. Diese anomale Absonderung scheint auch in den tiefen Respirationswegen ihren Sitz zu haben; man hört bisweilen Trachealrasseln und reichliche Lungengeräusche.

Das Mauen nimmt einen fremdartigen Ton an: es wird dumpf, heiser und bald geht es in totale Stimmlosigkeit über. Die Aphonie hat bei mehreren Katzen Wochen lang angehalten.

Vom ersten Erkrankungstage an rerlieren die Thiere ihre Fresslust und nehmen keine feste Nahrung mehr zu sich. Bald hören sie auf, Milch zu lecken und bleiben während 10 bis 12 Tagen ohne jegliche Nahrung.

Uebrigens ist es leicht, sich zu vergewissern, dass zuerst Dysphagie und bald darauf totale Aphagie besteht. Nicht allein, dass die Katze keine Trinkversuche mehr macht, sondern es wird auch die Milch, die mittels einer Pipette in den Schlund eingeführt wird, nicht heruntergeschluckt. Sie fliesst sofort zurück oder bewirkt Erstickungsanfälle, indem sie in die Trachea hineinfliesst. Wenn demnach das Thier auch der unmittelbaren Wirkung der Impfung entgehen würde, so würde es dennoch in Folge der andauernden Nahrungsenthaltung sterben. In der That scheint es bei mehreren unserer Versuche, als ob sich von einem gewissen Moment 
an eine beträchtliche Besserung im Allgemeinbefinden gezeigt hätte. Die Katze liegt nicht mehr auf der Seite, sie vermag sich aufzuriehten und den Kopf zu erheben. Selbst die Zunge ist zurückgezogen und die Schleimabsonderung hat nachgelassen. Nur die Stimme bleibt aphonisch, die Pupille erweitert und fast reactionslos. Kurz, man ist geneigt anzunehmen, dass die Wirkung des Schinkengiftes vorüber ist oder dass das Gift zum Theil wieder ausgeschieden ist. Würden die Thiere in diesem Stadium mittels Schlundsonde ernährt, so könnten sie wahrscheinlich vom sicheren Tode gerettet werden. Diese Annahme hat sich später. bei zwei Katzen bestätigt.

Während der ganzen Dauer der Krankheit sistirte in einzelnen Fällen die Urin- und Kothentleerung. Bei zwei kleinen Katzen, welche profuse Diarrhoeen hatten, wurden die Fäces ganz trocken.

Wenn man die Thiere in dieser Periode ansieht, erscheint ihr Verhalten sehr charakteristisch: die einen liegen die ganze Zeit über bewegungslos ausgestreckt, die anderen mit gekrümmten Rücken und Extremitäten, verlängertem Hals und bis zum Boden hängender Schnauze bleiben noch aufrecht. Bei allen prolabirt die Zunge und fliessen dicke, grauliche Schleimmassen aus dem Maul. Die Physiognomie ist ohne Ausdruck, die Augen unbeweglich und die Iris beinahe unsichtbar. Ist das Thier gezwungen, sich zu erheben, so bewegt es sich träge, es sucht eine dunkle Ecke auf, um sich zu verbergen. Nach wenigen Schritten legt es sich hin und erhebt sich nur mit grosser Mühe wieder von seinem Platze.

Dieser 'Zustand dauert 4 bis 5 Tage, bisweilen noch länger. Alsbald darauf bleibt die Bewegungsfähigkeit vollständig aus. Nach einigen Bemühungen fällt es sogleich auf die Seite zurück, den Körper regungslos zu Boden hingestreckt.

Bis in die letzten Stunden scheint die allgemeine Sensibilität und Auffassungsvermögen nicht ernstlich gelitten zu haben. Die Gliedmaassen contrahiren sich noch bei leichten Stichen, die Augen blinzeln noch beim Berühren der Cornea. Das Thier hört und sieht, aber die Starrheit des Blickes, die Aphonie, die generelle Muskelparese erlauben ihm nicht, seine Gefühle kund zu geben, und könnten an der vollständigen Erhaltung der Psyche zweifeln lassen.

Schwer ist es, sich genau von den Sehstörungen Rechenschaft zu geben. - Wie soll man eine Accommodationslähmung, deren Bestehen man doch vermuthen kann, objectiv feststellen?

Der Gang hat etwas Bemerkenswerthes; er ist unsicher, wankend und schwankend wie der eines Betrunkenen. Von Anfang an erkennt man eine Schlaffheit der Musculatur, die sich ebenfalls durch den Gang verräth. Nach einigen Schritten legt sich die Katze nieder, als ob ihre 
Kräfte erschöpft wären. Aufgejagt erhebt sie sich noch, aber fällt bald wieder zu Boden zurück.

Bei der ophthalmologischen Untersuchung boten die Augenbefunde mehrerer Thiere bis in die letzten Stunden nichts Auffallendes dar. Nur konnte ein gewisser Grad von Anämie der Retina constatirt werden. Strabismus, Exophthalmus, Ptosis wurden nicht beobachtet, aber mehrmals bestanden eitrige Entzündung und Hornhautgeschwüre, die durch Trockenheit und mangelnden Lidschluss $u$. s. w. hervorgerufen waren (Keratitis neuro-paralytica).

Um das Bild zu vervollständigen, erübrigt es uns noch, einige die Athmungs- und Circulationsfunctionen betreffenden Angaben hinzu zu fügen. Die Respiration ist während der zwei ersten Krankheitstage beschleunigt, verlangsamt und oberfächlich in den letzten. Die Temperatur ist normal oder subnormal, und fällt bedeutend iim Endstadium herab.

Locale Anschwellung, ödematöse oder entzinndliche Infiltration des Unterhautzellgewebes kommen nicht vor.

Der Tod wird durch Aufhebung der Respiration und Circulation, ohne jede Krampfanfälle oder spasmodische Contractionen, in vollkommener Muskelruhe hervorgerufen.

Die Thiere, welche ausnahmsweise am Leben geblieben sind, zeigten nur geringere Erscheinungen: Pupillenerweiterung, bisweilen sehr bedeutend und anhaltend, vorübergehender Prolaps der Zunge während eines oder zweier Tage, Wochen lang andauernde Stimmlosigkeit, Schlingbeschwerden, welche nach wenigen Tagen verschwanden, mässige Schleimsecretion u. s. w. Nur sehr langsam erreichten sie ihr ursprüngliches Gewicht wieder, oft war ihre Fresslust ausserordentlich gesteigert. Nicht selten beobachtete man blutigen Stuhlgang, kreidige Entleerungen, Haarausfall und ekzemartige Hautentzündungen.

Die makroskopischen Veränderungen bei der Obduction stimmen nicht mit der Schwere des Krankheitsbildes, welches zum Tode führte, überein; abgesehen von einem hyperämischen Zustand der Leber mit mehr oder weniger ausgebreiteter fettiger Degeneration, Congestion der Nieren, der Lungen mit hämorrhagischen Infarcten, Hepatisation u. s. w. ist nur hervorzuheben, dass Harn- und Gallenblase fast constant prall gefüllt sind. Die Milz ist blass und klein, Blut schwarz, flüssig. In dem Unterhautzellgewebe findet man an der Injectionsstelle gewöhnlich nur ein geringes Blutextravasat oder einige Tropfen dicken Eiters.

Bei den Kaninchen wirken grosse Dosen der Maceration ron 0.1 bis $\mathbf{0 . 5} \mathbf{5}^{\text {eem }}$ wie ein foudroyantes Gift. Nach einem Latenzstadium von 6 bis 10 Stunden werden sie oft plötzlich von ernsten Erscheinungen befallen und sterben nach einer viertel bis halben Stunde. Sie fallen 
vollständig gelähmt mit einem sehr scharfen Schrei auf die Seite und sterben unter Zuckungen in Folge Respirationslähmung.

Bei kleineren Dosen dauert das Latenzstadium 12 bis 18 Stunden, zuweilen sogar 36 bis 48 Stunden. Während dieser ganzen Zeit fressen die Thiere wie gewöhnlich. Nachher werden sie matt, apathisch; die Athmung ist beschleunigt, mehr oberflächlich und die Herzschläge nehmen an Schnelligkeit zu. Sie bewegen sich nicht, oft erheben sie den Kopf und scheinen nach Luft zu ringen. Die erweiterten Nasenlöcher, die Schnauze sind mit klarer, keineswegs klebriger Flüssigkeit benetzt. Entkräftet liegen sie auf dem Bauch mit verlängertem Hals und ausgestreckten Gliedern. Die progressir absteigende Paralyse wird in sehr kurzer Zeit generell.

Zuweilen beschränkt sich die Parese nur auf einzelne Muskelgruppen. Der Kopf făllt zur Seite, die vorderen Extremitäten sind ausgestreckt, die hinteren, unter den Leib gezogen, behalten ihre volle Kraft. (Vgl. Taf. III, Fig. 1.) Sonst sind die hinteren Extremitäten allein gelähmt und das Kaninchen schleppt sich mühsam auf den Vorderpfoten mit gehobener Schnauze weiter. Manchmal scheint auch nur ein Glied unbeweglich.

Gewöhnlich sind die Pupillen erweitert, bisweilen in einem sehr hohen Grade, stets wenig empfindlich gegen Lichtreiz. Ausnahmsweise beobachtet man eine Verengerung im Anfangstadium; sie geht schnell in eine mehr oder minder ausgesprochene Dilatation über. Unregelmässigkeit der Irisöffnung ist seltener; dieselbe ist beiderseits fast gleich gross. Die Bulbi erscheinen in mehreren Fällen bewegungslos, aus der Höhlung hervortretend, die Conjunctiva ist injicirt. Leichter Strabismus internus kommt manchmal vor.

Nach den ersten Krankungserscheinungen hört das Thier auf zu fressen und zu kauen. Die in den Rachen eingeführten Flüssigkeiten fliessen wieder zurück, als ob eine vollständige Aphagie bestände.

Bis zu den letzten Stunden scheinen die allgemeine Sensibilität und die Reflexe erhalten. Gänzliche Urinretention besteht oft während der Lähmungsperiode. Der Tod tritt in einem lethargischen Zustand nach Erstickungsanfällen ein und die ganze Erkrankungsdauer überschreitet selten 4 bis 6 Stunden.

Das Thier verendet in der durch die Paralyse bedingten Lage, die Glieder sind mehr oder weniger ausgespreizt, der Kopf hängt auf einer Seite herunter, durch die sehr schnell eintretende Leichenstarre fixirt.

Man beobachtet an der Injectionsstelle in den meisten Fällen absolut keine Veränderungen. Es entsteht niemals eine entzündliche Infiltration; höchstens bemerkt man zuweilen eine gewisse ödematöse Geschwulst ohne Temperaturerhöhung oder Röthe der Haut. 
Constant ist bei der Obduction die Hyperämie des Dünn- und Dickdarms. Congestion der Nieren und der Leber mit oft sehr ausgesprochener Degeneration fehlen selten. Die Blase ist meist mit klarem, eiweiss- und zuckerfreiem Urin angefüllt und oft ausserordentlich gedehnt. Die Lungen sind stark hyperämisch, zeigen Infarcte und manchmal gänzliche Hepatisation.

Makroskopische Veränderungen wie Oedem, Hämorrhagieen der Hirnund Rückenmarkshäute, sowie im Centralnervensystem, besonders in der Protuberanz und Medulla obl. in der Gegend des IV. Ventrikels sind mehrmals beobachtet worden.

Das Krankheitsbild bei den Meerschweinchen ist ganz dasselbe wie beim Kaninchen. Wir würden nur die Hauptzüge des vorher beschriebenen wiederholen können. Als frappantes Symptom heben wir den sehr reichen Speichelfluss und die vollständige Aphonie hervor. Das Meerschweinchen, welches bei der Berührung so scharf schreit, verstummt ganz.

Obne grossen Erfolg haben wir bei Kaninchen und Meerschweinchen chronisch verlaufende Erkrankungen zu erzielen versucht, indem wir ihnen kleine Dosen unter die Haut injicirten. In den meisten Fällen starben die Thiere unter acuten Erscheinungen, wenn die tödtliche minimale Dose erreicht wurde. Die nicht tödlichen Dosen, welche wir in Zwischenräumen von 2 bis 3 Tagen injicirten, wurden von einigen überlebt. Man erkannte dieselben wenig charakteristischen Symptome wie bei den durch eine einzige Dose spät verendenden Thieren. Obgleich ihre Fresslust oft sehr gross war, verloren sie allmählich an Gewicht, wurden ausserordentlich mager und marastisch.

Bei den Fröschen wurde die Maceration mehrere Male am Tag unter die Haut und in die Lymphsäcke eingespritzt, ohne die geringste Störung hervorzurufen.

Die Berechnung der kleinsten Dose, welche noch sicher in kurzem Zeitraum tödtet, hat nicht allein ein allgemeines Interesse. Sie bringt uns Licht über die Natur und das Wesen der nachtheiligen Veränderungen bei der Ellezelle'schen Schinkenvergiftung und lässt vermuthen, dass die krankheitserregenden Producte des Schinkens mit einer determinirten Toxicität begabt sind und nicht wie eine virulente Materie bei jeder Dosis ihre Wirkung entfalten.

Wenn man Thiere derselben Rasse, mit wenig Altersunterschied und denselben Bedingungen unterworfen, wählt, so beobachtet man, dass die geringsten Dosen der Maceration, die zur Tödtung eines Thieres nöthig 
sind, für dieselbe Art so ziemlich dieselben sein müssen: für Kaninchen, Meerschweinchen oder Mäuse.

Die Verschiedenheit der individuellen Widerstandsfähigkeit geht aus der mehr oder weniger langen Dauer der Krankheitserscheinungen hervor, aber gewöhnlich ist sie wenig charakteristisch.

Die Dosen, die stets nach dem Körpergewicht berechnet werden, sind natürlich nur zutreffend für dieselbe Anwendungsweise und für dasselbe Product, nämlich eine frisch bereitete Maceration (1:5).

1. Die minimale Dose ist beim Kaninchen 0.001 bis $0.002 \mathrm{~cm}$. Diese Dosis tödtet bei subcutaner Injection ein Thier von ca. $1 \mathrm{~kg}$ in spätestens 36 Stunden. Das Meerschweinchen lebt gewöhnlich bei derselben Dose 4 bis 6 Tage. Bei diesen Thieren variirt die kleinste letale Dosis zwischen 0.005 bis $0.006^{\mathrm{cm}}$.

Mäuse starben in 24 Stunden nach einer Einspritzung von $0.001 \mathrm{~cm}$ einer Dilution von 1/100 Maceration. Nimmt man also ein, Durchschnittsgewicht von $20^{\mathrm{grm}}$ an, so würde die tödtliche Dose nur $0.0005^{\mathrm{cm}}$ pro Kilo ausgewachsener Mäuse sein. Drei andere Thiere unterlagen ungefähr in derselben Zeit noch geringeren Dosen von 0.00025 bis $0.0001 \mathrm{~cm}$.

2. Der Tod ist unsicher bei Kaninchen und Meerschweinchen nach sehr'schwachen Dosen von 0.00025 bis $0.0001 \mathrm{ccm}$ und tritt erst am 3 . oder 4. Tag ein. Die Meisten werden augenscheinlich nicht krank. Einige sterben erst später an Cachexie. Die Krankheitserscheinungen treten gewöhnlich erst nach 12 bis 24 Stunden auf. Bisweilen stellen sich die ersten Lähmungssymptome, der Speichelfluss u.s.w. erst am 3. oder 4. Tag ein, oft sogar noch später und gehen dann dem Tod nur um einige Stunden voran.

3. Bei einer Dose von 0.01 bis $0.05 \mathrm{~cm}$ tritt bei derselben Thierart die letale Wirkung mit der grössten Schnelligkeit auf, der Tod erfolgt nach 18 bis 24 Stunden. Das Latenzstadium beträgt oft 10 bis 18 Stunden und darüber.

4. Sehr starke Dosen von $0.1^{\text {cem }}$ und darüber rufen acuteste Erscheinungen hervor, welche nur eine viertel bis eine halbe Stunde dauein können. Trotz dieser äusserst hohen Dosen besteht noch immer eine Latenz- oder Incubationsperiode von 6 bis 12 Stunden.

5. Nach sehr zahlreichen Versuchen müssen wir es als feststehende Thatsache betrachten, dass die Krankheitserscheinungen stets spät auftreten; die Störungen zeigen sich nicht eher nach Injection in die Blutbahn oder selbst unter die Hirnhäute als nach subcutaner Einspritzung. 
6. Schliesslich besteht ein ausgesprochenes Verhältniss zwischen der Intensität, der Dauer der Erscheinungen und der Grösse der Dosen. Sehr geringe Dosen, unter der Minimaldose, rufen beim Kaninchen, Meerschweinchen u.s. w. wenig charakteristische Störungen hervor, Cachexie u. s.w. Meistentheils bleiben sie wirkungslos. Schwache Dosen tödten in 48 Stunden, spätestens in 3 bis 4 Tagen; stärkeren Dosen unterliegen die Thiere in. 12 bis 18, mittleren in 24 bis 30 Stunden. Dieses Verhältniss zwischen dem toxischen Effect und der Dose fällt besonders in die Augen, wenn man sich widerstandsfähigerer Thiere, wie der Katze z. B. bedient, und lässt vermuthen, dass der Schinken eine toxische, lösliche Substanz enthält.

Es fragt sich nun, ob das Fleisch, bezw. die Maceration, in minimalen Dosen den Thieren verabreicht, stets genügende Mengen dieses Giftes schon enthält, um die auftretenden Erscheinungen zu erklären.

Das Filtriren auf Porzellan erlaubt diese Frage zu beantworten. Es hat ein steriles Product geliefert, welches auf Katzen, Mäuse, Kaninchen, Meerschweinchen u. s. w. dieselbe Wirkung und in genau derselben Dosirung ausübte wie das nicht filtrirte. Bei Katzen wurden durch dieses bakterienfreie Filtrat der Maceration dieselben charakteristischen Erscheinungen hervorgebracht, sowie dieselbe Protrahirung der Erkrankung, deren Dauer und Incubationsstadium übrigens in allem den Verhältnissen entsprachen, welche sich durch Thierversuche mit dem Schinken oder der unfiiltrirten Maceration ergeben hatten. Ausserdem zeigten die makroskopischen und mikroskopischen Veränderungen keinen Unterschied von den früher geschilderten. Nach Ingestion rief das sterile Filtrat fast dieselben Veränderungen des Magens und Darmes hervor, wie die Verfütterung des. Schinkenfleisches selbst.

Folgende Betrachtungen erlauben eine approximative Bestimmung der wirklichen Quantität des toxischen Agens, welches erforderlich ist, um. ein Thier von besimmter Art und Gewicht zu tödten. Nach Verdampfung und Ausglühen des Rückstandes wog die Asche von $100 \mathrm{~cm}$ Maceration $0.163 \mathrm{grm}$, gegen 0.212 des trockenen Rückstandes vor Incineration. Alsohaben die organischen Bestandtheile, unter welche das Gift zu rechnen ist, höchstens $0.049 \mathrm{grm}$ wiegen können. Diese ca. $50 \mathrm{mg}$ pro $100 \mathrm{~cm}$ Maceration, unter die Haut gespritzt, würden zur schnellen Tödtung von $100000 \mathrm{~kg}$ Kaninchen genügen. Dasselbe Quantum würde auf $1500 \mathrm{Men}-$ schen von je $70 \mathrm{~kg}$ Gewicht tödtlich wirken in dem Fall, dass beim Menschen dieselbe Empfindlichkeit für das subeutan injicirte Gift vorhanden wäre. Für den erwachsenen Menschen. soll deshalb die minimale 
Dosis $0.035 \mathrm{mg}$ nicht übersteigen. Wir können also mit Recht behaupten, dass der Ellezelles'sche Schinken eins der wirksamsten Gifte enthält, nur vergleichbar den gefährlichen Bakterientoxinen. Nach Brieger (60) würde das Tetanustoxin in ziemlich reinem Zustand einen Erwachsenen von $70 \mathrm{~kg}$ Gewicht bei einer Dosis von 0.13 mg tödten.

Da die Maceration des Schinkens in der That eine äusserst giftige Substanz enthält, scheint es überflüssig, eine weitere Giftproduction im Organismus selbst anzunehmen, um die pathologischen Erscheinungen, welche bei Menschen und Thieren beobachtet sind, zu erklären. Jedoch ist es nicht ohne Interesse, sich durch das Thierexperiment $\mathrm{zu}$ vergewissern, dass eine Vermehrung des giftigen Schinken-Mikroorganismus im Thierkörper selbst nicht statthat.

Eine endogene Intoxication ist nicht leicht anzunehmen. Im Blut, Urin u. s. w. der Thiere, die mit kleinen Dosen behandelt sind, war niemals genügend Gift vorhanden, um andere Thiere, wie Mäuse, Meerschweinchen, krank zu machen. Das Gift scheint sich ebenfalls nicht in inneren Organen anzuhäufen, was doch der Fall sein sollte, wenn die betreffenden Mikroorganismen sich im lebenden Körper in gewissem Grade vermehren würden. Grosse Stücke Leber, die ganze Milz, frischen Thierleichen entnommen, denen man 0.1 bis $\mathbf{0 . 5}$ cem Maceration injicirt hatte, und nach Zerreibung mit Bouillon unter die Haut eingespritzt, riefen keine Krankheitserscheinungen hervor. Im Gegentheil, wenn man Leber, Milz u. s. w. der durch minimale Dosen getödteten Kaninchen 18 Stunden im Brütapparat stehen liess und nacher in ziemlich hohen Dosen von $0.1^{\mathrm{cem}}$ Emulsion in Bouillon einspritzte, gelang es mehrmals, charakteristische Symptome bei weiteren Thieren hervorzurufen. Eine serienweise fortgesetzte Erkrankung würde also nur möglich sein, nachdem sich die Mikroorganismen im todten Gewebe fortentwickelt haben.

Von Wichtigkeit war es ferner, zú untersuchen, ob die Giftproduction sich nicht in bestimmten Organen localisirt, namentlich in den Speicheldrüsell und in dem Nervensystem. Nach einigen diesbezüglichen Experimenten können wir behaupten, dass weder das Gewebe der Speicheldrüsen noch die hauptsächlich afficirten Theile des Centralnervensystems irgendwelche toxische Wirkung bei den mit schwachen Dosen behandelten Kaninchen hervorrufen.

Schliesslich bleibt nur noch eine engere Localisirung der specifischen Mikroorganismen zu vermuten und deshalb festzustellen, ob sie sich nicht im Bereich der Injectionsstelle selbst vermehren, z. B. im Unterhautzellgewebe nach subcutaner Injection oder im Intestinaltractus nach Verfütterung. Man keunt doch mehrere Bakterienarten, die des Tetanus, der Diphtherie, der Cholera, welche so zu sagen nur in den äussersten 
Grenzen der Oekonomie, auf der Oberfläche der cavitären Schleimbäute, leben und im Blut sowie in den parenchymatösen Organen schnell zu Grunde gehen. Wie aus der ausserordentlich grossen Activität des Schinkengiftes hervorgeht, wtrde eine sehr geringe, unmerkliche Vegetation der inoculirten Mikroorganismen genügen, um schnell die tödtlichen Symptome hervorzurufen. Es scheint jedoch weder im Subcutangewebe noch im Peritoneum eine merkliche Giftproduction stattzufinden. Nach Einspritzungen von mittleren Dosen beim Kaninchen und Meerschweinchen wurde das Unterhautzellgewebe excidirt, das Peritoneum mit Bouillon ausgewaschen 4, 6, 8 und 10 Stunden nach der Injection. Die Meerschweinchen, welchen man die Bouillon injicirte oder denen man die exicidirten Stücke unter die Haut einführte, blieben alle gesund, nur eins ging nach 17 Tagen cachetisch zu Grunde.

Man konnte doch wohl die Vermathung hegen, dass wenigstens der Darm einen günstigen Nährboden für die Entwickelung der giftigen Schinkenbakterien abgeben würde. - Um so mehr, als der Intestinaltractus für zahlreiche Saprophytenarten, unter denen die Anaëroben nicht fehlen, ein angepasstes Medium bildet, auf dem sie sich, geschützt gegen die abwehrenden Momente der lebendigen Gewebe und Körpersäfte, nach Willkür rerbreiten können. Durch den Versuch erwies sich diese Hypothese als hinfällig.

Ein wässeriger Schinkenextract, welcher 10 Monate lang der Luft ausgesetzt war, zeigte sich ohne jede Wirkung, auch nach Einverleibung sehr grosser Dosen. Nichtsdestoweniger erhielten wir nach Zusatz einiger Tropfen dieses Extractes zu gekochtem sterilisirten Fleisch ein sehr toxisches Product, in welchem es von den. ursprünglichen anaëroben Bacillen wimmelte. Ausserdem wurde der Inhalt des Dünndarms und Coecums eines Meerschweinchens, dem man $5^{\mathrm{cm}}$ frische Maceration eingegeben hatte und das nach 24 Stunden starb, mit 10 ecm Bouillon gemischt. Diese Mischung wurde Mäusen ohne Erfolg verfüttert.

Alle unsere Experimente berechtigen uns demnach zu dem Schlusse: es bildet sich kein Gift im lebenden Thiere; die Mikroorganismen, welche der Schinken enthält und welche demselben das Gift übermitteln, vermehren sich weder im Darm, noch in den Geweben. Es sind wahre Saprophyten, welche wie die grossen giftigen Pilze durch das in ihrem Protoplasma und in den todten Substraten, auf welchen sie sich entwickelt haben, enthaltene toxische Princip Vergiftungserscheinungen hervorrufen.

Diese Ergebnisse der mit dem Schinken gemachten Versuche sind mehrmals controlirt worden durch Experimente, welche wir in derselben Weise mit Culturen des anaëroben Bacillus angestellt haben, und deren 
Resultate am Schluss dieser Arbeit erwähnt werden. Nur wollen wir hier noch angeben, dass das Fehlen jeder Giftbildung im lebenden Organismus sich auch voraussehen liess durch das Vorhandensein von sehr wenig zahlreichen specifischen Bakterien in den Organen der Thiere, die mit dem Schinken behandelt waren, wie aus den histologischen Untersuchungen und aus den Culturversuchen hervorgeht.

Warum die widerstandsfähigen und zahllosen Mikroorganismen, die in das Blut, die Gewebe und auch in die Verdauungswege eingeführt sind, daselbst nicht eine ansehnliche Menge des so wirksamen, in dem Sehinken enthaltenen Toxins produciren, wollen wir noch zu erklären versuchen. Entweder handelt es sich um eine Bakterienart, die sich dem Thierkörper nicht anpassen kann, oder der lebende Organismus verfügt über Abwehrmittel, die dieselben alsbald zu vernichten im Stande sind. Die Richtigkeit dieser Hypothesen könnte nur mit Hülfe der Culturen des Mikroorganismus, welchem das verdächtige Fleisch seine toxische Wirkung verdankt, festgestellt werden.

Die Uebereinstimmung der im Thierexperiment zu Tage getretenen pathologischen Erscheinungen mit dem Krankheitsbild zu Ellezelles scheint uns so einleuchtend, dass es schwer sein würde, ihre gemeinschaftliche Aetiologie zu leugnen. Die Aehnlichkeit besteht nicht nur bezüglich der eigenartigen Symptomatologie, sondern ist auch in den anatomischen Veränderungen begründet.

Der Obductionsbefund bei den Thieren ist im Wesentlichen derselbe wie bei den menschlichen Leichen. Die makroskopischen Veränderungen sind weder charakteristisch, noch im Stande die ernsten Erscheinungen sowie die Ursache des schnellen Todes zu erklären.

Fine genaue, histologische Untersuchung der Organe konnte uns näheren Aufschluss über die Veränderungen geben. Wir fassen hier nur die hauptsächlichen Resultate dieser Untersuchung zusammen und werden später nochmals darauf zurückkommen. Der hyperämische Zustand der verschiedenen Organe scheint primärer Art und durch eine Alteration der Gefässwände bedingt zu sein. Die Endothelien bieten die bei toxischen oder infectiösen Erkrankungen so häufigen granulirt-fettigen Degenerationen u.s.w. Sie kommen in allen Geweben vor. Mikroskopisehe diffuse Hämorrhagien sind im Darm, Magen, Leber, Nieren, Lungen, Muskeln und Centralnervensystem stets aufgefunden worden. In den nervösen Elementen localisiren sie sich oft in gewissen Gebieten tes Rückenmarkes (Katzen, Kaninchen, Affen) und fehlen nur selten in Medulla oblongata und Protuberanz.' Obwohl diese Gefässverletzungen theils während des asphyctischen Stadiums entstehen und mechanische Störungen hervorrufen, 
lassen sich dieselben doch nicht genügend durch die Athmungs- und Circulationslähmung erklären. Uebrigens sind sie bei den im Anfangsstadium der Intoxication getödteten Thieren beobachtet worden und zeigten in den untersuchten Fällen valle Grade, alle Uebergänge, welche ihre Entstehung stufenweise verfolgen liessen.

Im Anschluss an diese hyperämischen Veränderungen der Bauchund Brustorgane treten häufig entzündliche Infiltrationen auf. Die interstitielle Hepatitis, deren Vorhandensein Souchay und wir nach Vergiftung beim Menschen constatirten, ist häufig bei unseren Thieren beobachtet worden. Leukocytäre Einwanderung im Bronchieen-, Lungen-, Darm- und Muskelgewebe wurde auch beobachtet. In den Magenwandungen, besonders nach Verfütterung, sind entzündliche bis nekrotische Herde mehrmals aufgetreten. Selbst nach einer Erkrankungsdauer von nur 24 Stunden wird fettige Degeneration der Leber, der Nieren, des Myocards gefunden.

Die submaxillaren Speicheldrüsen bei Katze, Meerschweinchen u. s. w. zeigen ebenfalls Hyperämie und einen eigenartigen mucösen Degenerationszustand der secretorischen Zellen, der uns bemerkenswerth scheint.

Endlich beobachtet man im Centralnervensystem, in den Vorderhörnern und in den Bulbärkernen u. s. w. gewisse Veränderungen der motorischen Nervenzellen, welche wir besonders noch hervorheben möchten.

Alle diese Läsionen sind jedenfalls toxischen Ursprungs, denn die gewöhnlichen Methoden der Bakterienfärbung haben keine Mikroorganismen finden lassen.

In einer vorläufigen Mittheilung haben wir die Analogie zwischen der experimentellen Intoxication, den klinischen Erscheinungen zu Ellezelles und dem Botulismus im Allgemeinen hervorgehoben. Es sei uns erlaubt einige unserer Schlüsse hier zu wiederholen. „Die Erscheinungen, welche bei der Katze auftreten, sind derart, dass man sie mit Recht den pathognomischen Symptomen des Botulismus parallel stellen kann. Sie sind: beträchtliche und andauernde Mydriasis, Aenderung der Pharyngeal- und Bronchialsecretion, verschiedene partielle Paresen, welche sich unter anderem bemerkbar machen durch Prolaps der Zunge, Aphonie, Aphagie, croupartigen Husten, Retention des Harns, der Galle u. s. w. In zweiter Linie kommt die Taube. Ausser der Parese der Flügel zeigt sie andere interessante Lähmungserscheinungen, wie Ptosis, Ungleichheit der $\mathrm{Pu}$ pillen u. s. w. Die Kaninchen und Meerschweinchen, wie die Affen, sind ebenfalls sehr empfindlich. Diese Thiere, per os vergiftet, zeigen ausgesprochene paretische Störungen" (61).

Kurz, bei empfindlichen Thierarten beobachtet man ein Erkrankungsbild, den botulinischen Symptomencomplex sehr ähnlich und bestehend in 
Störungen der Secretionsapparate und Paresen, die hauptsächlich Muskelgruppen betreffen, deren Nerven ihre Ursprungskerne in $\mathbf{M}$. oblongata und Pons haben: N. oculo-motorius communis u. ext., N. facialis, N. glossopharyngeus, N. vagus, N. hypoglossus u. s. w. Wenn die Wirkung des Ellezelles'schen Schinkens in einzelnen seiner Erscheinungen bei gewissen Thieren von der beim Menschen abweicht, so genügen doch die Verschiedenheiten des anatomischen Substrates, um sie verständlich zu machen.

Wir glauben also mit Recht behaupten zu können, dass die Empfänglichkeit verschiedener Thierarten für den Botulismus nicht mehr zu bestreiten ist.

Wir haben keine Versuche gemacht, um das active Princip des Schinkens zu extrahiren. Es genügte für unseren Zweck, einige seiner hauptsächlichsten Eigenschaften festzustellen und es den gewöhnlichen Methoden des Ptomainnachweises zu unterziehen.

Ebenso wie mehrere Toxine, das Tetanustoxin und das Diphtherietoxin u.s.w., ist das Schinkengift ziemlich unbeständig und verliert allmählich seine Toxicität, wenn es der Luft und Licht ausgesetzt ist. Der wässerige Extract, in zugeschmolzenen Röhren und im Dunkeln aufbewahrt, behält dagegen seine volle Wirkung noch nach 10 Monaten. Selbst nach 8 Monaten tödtete die minimale Dose in 24 bis 36 Stunden die Kaninchen $\left(0.001^{\mathrm{ecm}}\right)$. Das Fleisch scheint noch besser seine toxischen Eigenschaften zu bewahren. Kleine Stückchen, ohne besondere Vorsichtsmassregeln in einer mit Watte verstopften Tube aufbewahrt, sind 17 Monate nach den Ellezelles'schen Unfällen untersucht worden. Ein stecknadelkopfgrosses Stück unter die Haut gebracht, tödtete Kaninchen nach 2 bis 3 Tagen.

Höheren Temperaturen gegenüber scheint das Gift wenig widerstandsfähig. Die Giftigkeit eines filtrirten wässerigen Extractes hat schon nach 3 Stunden Einwirkung einer Temperatur von $58^{\circ}$ bedeutend eingebüsst. Gegen $70^{\circ}$ während einer Stunde erwärmt, tödtet der Extract nur bei sehr starken Dosen. Eine Temperatur von $80^{\circ}$ macht ihn fast unwirksam nach einer halben Stunde. Es bedarf einer Dosis von $10 \mathrm{com}$ beim Kaninchen um Erscheinungen hervorzurufen. Die Thiere verendeten nach mehreren Wochen im Cachexie. Dies Filtrat verliert bei $100^{\nabla}$ jede Wirkung in sehr kurzer Zeit. Kleine Stückchen Schinkens in kochendes Wasser gelegt und nach 5, 10, 15 Minuten herausgenommen, wurde Mäusen eingeimpft, aber riefen nicht die geringste Störung hervor.

Wenn der Ellezelles'sche Schinken vor dem Genuss gekocht oder gebraten worden wäre, anstatt roh gegessen zu werden, würden auch keine Erkrankungsfälle aufgetreten sein. 
Schnelle Austrocknung bei $\mathbf{3 7 ^ { \circ }}$ änderte nichts an der Wirkung des filtrirten Fleischextractes, sein trockener Rückstand bewährte Monate hindurch seine Toxicität.

Das Gift scheint nur ziemlich langsam zu dialysiren. Wenigstens hat die Membran nach 18 bis 20 Stunden erst genügend von dem giftigen Stoffe in $100^{\mathrm{cm}}$ destillirtes Wasser durchgelassen, um bei Dosen von $5 \mathrm{ccm}$ Kaninchen in 2 Tagen zu tödten.

Der Verfaulung widersteht das active Princip des Schinkens jedenfalls gut. Filtrirter Extract vermischt mit Koth, verdorbenem Blute, Urin in ammoniakaler Zerseţung und 4 Tage nachher auf Porzellan filtrirt, hatte bei Dosen von $1,0.1$ und $0.01 \mathrm{~cm}$ noch eine intensive Wirkung. B. prodigiosus, B. proteus liquefaciens, B. fluorescens putridus, B. coli wurde in ein frisches Filtrat ausgesät und nach achttägiger Cultur Kaninchen eingespritzt. Die Thiere sind alle früher oder später gestorben.

So wenig veränderlich der wirksame Stoff des Schinkens in Säurelösung erscheint, um so unbeständiger ist er in alkalischer.

$10 \mathrm{ccm}$ Fleischmaceration wurde filtrirt und 1 bis 3 procent. Weinsäure, Milchsäure, 1 bis 0.5 pro mill. Salzsäure zugegeben. Nach 24 Stunden bei $35^{\circ}$ hatten die Mischungen noch ihre volle Wirkung behalten und tödteten wie vorher bei $0.001 \mathrm{ccm}$ pro Kilo Kaninchen.

Dagegen konnte von demselben Filtrat, dem man zu gleichen Theilen eine $0.5,1$ und 3 prozent. Natronlösung zufügte, nach 24 Stunden eine 50 bis 100 fach tödtliche Dosis Kaninchen ohne ernstere Folgen injicirt werden. Die Alkalisation wirkt sozusagen augenblicklich, schon nach 5 bis 10 Minuten ist die Giftigkeit aufgehoben. Da das Gift vielleicht nur in Gegenwart von Säuren seine Wirkung ausübt, haben wir nach Alkalisation noch das Filtrat neutralisirt oder einen Säureüberschuss von 1 bis 0.5 Procent gegeben. Auch sehr starke Dosen von 1 bis $5^{\text {ccm }}$ blieben ganz wirkungslos.

Von der Hypothese ausgehend, dass das toxische Agens eine Ptomainbase sein könnte, haben wir eine Reihe von Reagentien, welche diese Basen lösen oder fällen, durchprobirt. Es ist nicht merklich löslich :in Chloroform, Aether, Benzol oder Amylalkohol, weder nach Ansäuerung noch nach leichter Alkalisirung des Filtrates. Die ausgeschüttelten Flüssigkeiten behielten ihre volle Wirksamkeit. Zufügung von Goldchlorid, Platinchlorid, Sublimat bis 1 Procent vernichtet das Gift vollständig. Im Gegentheil, die durch Alkohol, Tannin, Schwefelsäureammoniak erhaltenen Niederschläge sind sehr activ.

Kurz das Princip, welchem der Ellezelles'sche Schinken seine Giftigkeit verdankt, besitzt im Allgemeinen die Eigenschaften der noch nicht 
weiter chemisch definirten Substanzen, welche unter dem Namen von Toxinen bekannt sind. Ebenso wie das Diphtherietoxin, das Tetanustoxin verliert es unter dem Einfluss wenig höherer Temperaturen, von zerstreutem Tageslicht und Luftsauerstoff seine Wirksamkeit; es ist wie diese Toxine fast unlöslich in Amylalkohol, Aether, Chloroform u.s.w. Ferner ist es den Alkalien gegenüber besonders empfindlich, in geringerem. Grade den Säuren gegenüber. Durch Alkohol, Tannin, Neutralsalze u.s.w. wird es gefällt. Die Lösungs- und Fällungsmittel, welche gewöhnlich zur Extraction der Ptomaìne dienen, geben höchstens eine sehr kleine Ausbeute an toxischen Producten.

Obwohl das Fleisch des zweiten Schinkens, trotz des vorgeschrittenen Fäulnisszustandes keine Erkrankungen hervorgerufen hatte, haben wir nichtsdestoweniger seine Wirkung beim Thier untersucht. Es war nicht ohne Interessse, experimentell seine Unschädlichkeit zu demonstriren, da es augenscheinlich doch unter denselben Bedingungen wie der giftige Schinken gesalzen und conservirt worden war. Aus den verfaulten Theilen, sowie aus den mehr oder weniger gesunden Theilen wurde in. derselben Weise wie aus dem anderen Schinken eine wässerige Maceration bereitet. Ferner wurde das Fleisch als solches zu essen gegeben. Yäusen, Ratten konnten męhrere Tage nach einander grosse Quantitäten verfüttert werden; nur eine weisse Maus starb ohne nennenswerthe Läsionen, sämmtliche anderen blieben gesund. Bei Aufnahme vom Magen aus war die Maceration bei Dosen von 10 bis $40 \mathrm{~cm}$ ganz wirkungslos auf Meerschweinchen und Kaninchen. Bei subcutaner Injection starben einige Mäuse und Ratten; Meerschweinchen und Kaninchen zeigten keine Spur von Erkrankung, Katzen erhielten 5 bis 10 com ohne jegliche Wirkung.

Die relative Ungiftigkeit des faulen Schinkens, das Fehlen jeder specifischen Wirkung bei so empfindlichen Thieren wie Kaninchen, das totale Ausbleiben botulinischer Erscheinungen bei den verendeten Thieren beweist deutlich, dass dieses Fleisch überhaupt keine Spuren des im verdächtigen Schinken so reichlich vorhandenen Giftes enthält. Unwahrscheinlich ist es, dass durch den nach dem Pökeln aufgetretenen Fäulnissprocess das Gift zerstört worden sei. Wir sind deshalb genöthigt anzunehmen, dass die zwei Schinken desselben Schweines, obwohl sie zusammen in demselben Fass eingesalzen wurden, doch nicht dieselben Veränderungen erlitten haben.

Um ihre so verschiedene Wirkung auf Menschen und Thiere erklären zu können, giebt es nur eine einzige plausible Hypothese. Der giftige Schinken befand sich auf dem Boden des Gefässes in einem wahr- 
scheinlich zu wenig concentrirten Salzwasser; der zweite, darüber liegende und von ersterem nur durch eine Schicht Speckstücke getrennt, war vollständig ausserhalb der Lake. Für den ersten Schinken allein waren also Bedingungen vorhanden, welche die Entwickelung der Anaëroben gestatten; auch er allein enthielt zahlreiche Mikroorganismen, die nur bei Luftabschluss gedeihen.

Aus den Versuchen, welche bei den Thieren mittelst des verdächtigen Nahrungsmittels von Ellezelles angestellt wurden, können folgende Schlüsse gezogen frerden:

1. Der Schinken, der am 14. December 1895 durch die Mitglieder des Musikvereines genossen wurde, enthielt eine lösliche äusserst giftige Substanz, die bei verschiedenen Thierarten, durch Aufnahme vom Magen aus sowie durch subcutane Injection u. s. w. charakteristische Erscheinungen hervorruft, deren Aehnlichkeit mit dem Botulismus nicht zu leugnen ist.

2. Die durch den Fleischgenuss erzeugten Störungen scheinen ausschliesslich ectogener Natur und durch das im Schinken präformirte Gift bedingt zu sein.

Der Harn von zwei schwer erkrankten Personen war wirkungslos bei Kaninchen u. s. w.; ferner fehlten jegliche specifische Erscheinungen bei den Thieren, welchen man hohe Dosen wässeriger Extracte der einzelnen Organe eines der Verstorbenen verabreichte.

Weder nach Aufnahme des Schinkenextractes vom Magen aus, noch bei Einführung ins Blut, Peritoneum, unter die Haut u. s. w. konnte man in den thierischen Organen (Leber, Nieren, Speicheldrüsen, Nervensystem u. s. w.) eine weitere Production ron giftigen Stoffen feststellen.

3. Das Schinkengift ist von den Fäulnissproducten, welche in einem der Schinken vorhanden waren, ganz und gar verschieden. Das verfaulte Fleisch ist übrigens vom Menschen und von Thieren ohne grössere Störung genossen worden.

4. Durch seine sehr charakteristische Wirkung, seine sehr hohe Toxicität, seine geringe Resistenz gegenWärme, Licht u.s.w., seine Zersetzbarkeit durch Alkalien und manche Reagentien steht dieses Gift den Bakterientoxinen sehr nahe.

Höchst wahrscheinlich ist es im Schinken, während der Einsalzungszeit, durch anaërobe Wucherung gewisser specifischer Mikroorganismen entstanden. 
III.

Für unsere bakteriologischen Untersuchungen hatten wir zur Verfügung die Reste der zwei Schinken, Harnproben von zwei Kranken, mehrere Organe einer obducirten Leiche und endlich eine grosse Zahl verendeter Thiere, welche mit dem verdächtigen Schinken geimpft waren.

Aërobe Plattenculturen des giftigen Schinkens wurden wiederholentlich mit bald aus der Tiefe, bald von der Oberfläche, bald in der Nähe des Knochens entnommenen Gewebsstücken angelegt. Die auf diese Weise isolirten Mikroorganismen waren stets wenig zahlreich und gehörten alle zu den gewöhnlichsten Arten. Ein weisser Micrococcus, welchen man mit dem M. tetragenus Gaffky identificiren möchte, war der einzig constante. Vom M. tetragenus unterschied er sich jedoch durch seine äusserst geringe pathogene. Wirkung und durch eine leichte Verflüssigung der Gelatine.

Anaërobe Culturen wurden nach der Botkin'schen Methode angestellt unter der Fürsorge, dass man reichlich mittels des ausgezeichneten Apparates von L. de Koninck (62) entwickelten Wasserstoff durchströmen liess. Auf Gelatine mit 2 proc. Traubenzucker erschienen nach achttägiger Cultur zahlreiche Colonieen, alle tiefliegend, verflüssigend und $z u$ verschiedenen Typen gehörend. Die einen waren klein, kreisrund, ziemlich durchsichtig und merkwürdiger Weise aus Körnern, welche sich fortwährend wie in einem langsamen Strom an der Peripherie der Colonie bewegten, zusammengesetzt. Die anderen waren mehr ausgestreckt, bis $2^{\mathrm{mm}}$ gross, mit sternförmig, cocardenartig eingeschnittenen Rändern u. s. w. oder kleinen Luftbläschen gleich, mit granulirten Massen im Centrum. Neben diesen Colonieen, welche alle aus grossen, mit abgerundeten Enden, öfters birnförmigen oder clostridiumartigen Bacillen gebildet waren, zeigten sich noch zahlreiche sehr kleine, nur unter dem Mikroskop sichtbare, total runde, mit glatten Rändern, dunkelbraun gefärbte und grobkörnige Colonieen. Dieselben bestehen aus tetradenähnlichen Kokken.

Diese anaëroben Culturversuche wurden oft mit frischen wässerigen Aufgüssen des Schinkens, oder mit auf $58^{\circ}, 70^{\circ}$ erwärmten, oder mit Carbolsäure, Chloroform behandelten Extracten wiederholt. Ferner wurden Platten mit Fleischstücken, die verschiedenen Stellen des Schinkens entnommen waren, besät. Endlich machten wir Plattenculturen mit sterilisirtem Schweinefleisch, dem Partikelchen von dem verdächtigen Schinken oder seiner Maceration zugefügt waren. Der Nährboden wurde variirt, unter Anderem wurde statt Glucose ameisensaures Natron u. s. w. genommen. Auf allen Nährboden erhielten wir bei allen Versuchen fast immer, mehr 
oder weniger zahlreich, die grobkörnigen, beweglichen Colonieen, die aus den oben beschriebenen grossen Bacillen bestanden. Je nach dem Alter der Cultur befanden sich daneben mehr ausgebreitete, eingebuchtete Colonieen. Letztere stellen nur ein weiter fortgeschrittenes Entwickelungsstadium der bewegliehen Colonieen dar, wie es durch die Reinculturen bestätigt wurde. Die Tetradencolonieen fehlten selten. Von Zeit zu Zeit fanden sich noch nebenbei einige Colonieen gewöhnlicher Bakterien, wie B. coli.

Um annähernd die Zahl der versehiedenen Mikroorganismen in einem bestimmten Quantum des Schinkens oder der Maceration abzuschätzen, wurden kleine Stückchen Muskelfleisch und Speck gewogen und nach Verimpfung in Zuckergelatine zu Platten gegossen. In einem Versuche wurden ungefähr 250 Colonieen des anaëroben Bacillus in $0 \cdot 1 \mathrm{grm}$ Speck gefunden, während das Muskelfleisch 49000 Colonieen enthielt. Der wässerige Extract zeigte einen besonderen Reichthum an diesen Mikroorganismen: $1^{\mathrm{com}}$ ergab im Durchschnitt 1 bis 3000000 Colonieen. Derselbe Extract wies 1 bis 5000 Colonieen von Aëroben auf. Diese stehen also im Verhältniss zu den Anaëroben wie 1:2000 bis 1000. Zwei von sechs mit Muskelfleisch beschickte Culturen blieben total steril oder wiesen nur Tetradencolonieen auf. Auch in drei Speckproben wurden die anä̈roben Bacillen vermisst, zweimal dagegen gelang es, dieselben aus dem Speck zu züchten, aber sie waren stets sehr spärlich vorhanden (30 bis 40 Colonieen) im Verhältnisse des zahlreichen Vorkommens in gewissen Theilen der Muskelsubstanz. Endlich bei Züchtung von sehr grossen Massen Knochenmark des verdächtigen Schinkens blieben alle anaëroben wie aëroben Plattenculturen stets steril.

Aus den bakteriologischen Untersuchungen des giftigen Schinkens können wir also schliessen: dass dieses Fleiseh durch die Sporen eines grösseren anaëroben Bacillus inficirt ist; - dass diese Mikroorganismen sehr unregelmässig in der Masse vertheilt sind, so dass sie an mehreren Stellen des Muskelfleisches und Speckes total fehlen; - nur sehr selten im Speck vorkommen und im Knochenmark gar nicht rorbanden sind; - endlich dass constant neben diesem deutlich überwiegenden anaëroben $\mathrm{Ba}$ cillus nur ein dem M. tetragenus ähnlicher Coccus vorkommt.

Der beim Genuss unschädliche Schinken enthält den in dem giftigen Fleische so zahlreich vorhandenen anaëroben Bacillus nicht. In den der Fäulniss anheimgefallenen Stellen finden sich zahllose aërobe Fäulnisserreger, wie B. proteus, B. coli u. s. w. Die normal aussehenden Theile des Sehinkens sind vollkommen keimfrei, im Gegensatz zu dem augen- 
scheinlich normalen Fleisch des verdächtigen Schinkens, welcher stellenweise von sehr zahlreichen anaëroben Bakterien durchwuchert war.

Bei der bakteriologischen Untersuchung des Harns von zwei Kranken wurden diese Mikroorganismen nicht aufgefunden.

Die aëroben Platten der menschlichen Organe, Nieren, Leber, Milz u. s. w. wiesen zahllose Colonieen des typischen B. coli und spärliche milchfarbige Sarcine- und Tetradencolonieen auf. Die anaërobe Cultur, leider 12 Tage nach dem Tode angestellt, zeigte dieselben Arten, nur auf den Platten der Milz fanden sich ungefähr 40 grobkörnige, bewegliche Colonieen, aus einem grossen Bacillus bestehend, welcher in jeder Hinsicht mit dem des giftigen Schinkens identisch ist. Magen- und Dickdarminhalt ergaben ebenfalls sehr spärliche Colonieen dieser Art. Weisse Mäuse und Ratten mit menschlichen Organen gefüttert, starben bald darauf; subcutane Einspritzung war ebenfalls tödtlich bei diesen Thieren innerhalb einiger Stunden. Dagegen blieben Kaninchen und Katzen am Leben nach Injection höherer Dosen. Aërobe Culturen der Organe verstorbener Thiere waren mit zahlreichen Colonieen des B. coli und spärlichen weissen Sarcine- und Mikrokokken-Colonieen besetzt. Anaërobe Culturen blieben meistens steril oder zeigten nur gewöhnliche Arten. Wir glauben also schliessen zu können, dass der Tod der mit Organen eines in Ellezelles verstorbenen Kranken geimpften Thiere nur durch die Culturproducte des $B$. coli verursacht ist.

In den mit Leber, Milz, Niere, Blut u. s. w. von mit Schinken geimpften Thieren gemachten Ausstrichpräparaten waren niemals Mikroorganismen zu entdecken. In den Exsudaten, im Subcutangewebe' fehlten sie gewöhnlich nach Einspritzung der Maceration beim Kaninchen, Meerschweinchen, Mäusen, sowie im Eiter bei der Katze. Höchstens waren in den Präparaten seltene Sporen und mehr oder weniger Mikrokokken und Tedraden zu sehen.

Diese mikroskopischen Untersuchungen, welche sehr oft und zu verschiedenen Zeiten nach der Inoculation wiederholt wurden, machen es unwahrscheinlich, dass der anä̈robe Schinkenbacillus sich local oder in den entfernten Organen merklich vermehrt hat. Die mit den Exsudaten, Blut, Organen, den frischen Leichen entnommen, angelegten Culturen bestätigèn ebenfalls diese Ergebnisse. In den überwiegend meisten Versuchen blieben die aëroben wie die anaëroben Platten fast keimfrei oder es entwickelten sich nur gewöhnliche Arten, wie Bact. coli u. s. w. Jedoch zeigte eine Anzahl von Platten, besonders die mit Eiter, Exsudaten angelegten, ziemlich zahlreiche Colonieen des M. tetragenus. Die Aussaat ron mehreren Cubikcentimetern Blut, grossen Stücken 
Leber, ganzer Milz u. s. w., wëlche während 18 Stunden im Brütkasten verweilt hatten, oder der Leiche erst 24 Stunden nach dem Tode entnommen worden, bot bei anaërober Züchtung mehr oder weniger verdächtige Colonieen.

Von den zwei Bakterienarten, die man bei der Schinkenvergiftung des Menschen und der Thiere in Betracht ziehen könnte, scheint die dem M. tetragenus ähnliche nur eine untergeordnete Rolle zu spielen. Durch sein Verflüssigungsvermögen auf Gelatine, welch letzteres sehr wenig ausgesprochen ist und oft ganz fehlt, durch seine geringe Virulenz für Mäuse, Meerschweinchen unterscheidet sie sich bestimmt von dem typischen M. tetragenus. Jedenfalls sind seine Culturen durch Aufnahme vom Magen aus wirkungslos. Bei Katzen haben wir $10 \mathrm{bis} 20^{\mathrm{ccm}}$ Bouillonculturen unter die Haut gespritat, ohne die geringsten charakteristischen Symptome hervorzurufen.

Der anarobe Bacillus, gleichviel ob er aus dem Schinken oder aus der Milz eines der Verstorbenen oder aus den Organen der geimpften Thiere stammte, besitzt stets dieselben morphologischen Merkmale. Er ist ungefähr 4 bis $9 \mu$ lang und 0.9 bis $1.2 \mu$ dick, stellt ein gerades Stäbchen mit etwas abgerundeten Enden dar und gleicht ziemlich den Milzbrand- und Oedembacillen (vgl. Taf. I, Fig. 3). Selten sind die Stäbchen nicht isolirt, bisweilen sind sie zu zweien oder in sehr kurzen Fäden aneinander gereiht. Spindelformen, clostridiumähnliche, sind gewöhnlich auf den Platten und in den Agar-, Gelatineculturen vorhanden. Involutionsformen beobachtet man in den wenig zusagenden Nährböden.

Sporenbildung tritt unter gewissen Bedingungen auf. Am Ende der Stäbchen, nur selten in der Mitte, entwickeln sich ovale, längliche Körper, etwas dicker als die Stäbchen selbst, welche der gewöhnlichen Färbung widerstehen (vgl. Taf. I, Figg. 4 u. 5). Temperatur, Zusammensetzung und Alkalescenz des Nährbodens beeinflussen die Sporenbildung. Am constantesten tritt sie auf in Gelatineculturen, welche stark alkalisch reagiren und denen man 2 Procent Traubenzucker zugesetzt hat. Ueber $35^{\circ}$ bleibt die Sporulation fast immer aus.

Der Bacillus ist nur schwach beweglich und mit ziemlich langen 4 bis 8 wellenförmigen Geisseln ausgestattet, welche mit der Löffler'schen oder Bunge'schen Methode zu färben uns nicht gelungen ist, wohl aber mit der von uns angegebenen Silbermethode (63). Er widersteht der Färbung nach Gram, nur muss die Wirkung des Alkohols controlirt werden.

Das Aussehen der jungen Colonieen in Zuckergelatine ist gewöhnlich 
so sehr charakteristich, dass man sie von anderen verbreiteten Anaëroben unterscheiden kann. Die 4 bis 6 Tage alten Colonieen sind bei 40 bis 60 facher Vergrösserung kreisrund, durchsichtig, von hellgelb-brauner Farbe und aus ziemlich groben lichtbrechenden Körnern, welche in continuirlicher Bewegung besonders an der Peripherie stehen, zusammengesetzt. Ringsherum befindet sich eine geringe Verflüssigungszone. Später werden sie fast undurchsichtig und lassen nur noch am Rande einen Saum beweglicher Körner hindurchscheinen. Die Peripherie ist wie mit einer Reihe kurzer Stächelchen besetzt. - In einem noch weiter vorgeschrittenen Stadium ändert sich das Aussehen gänzlich; die Colonie breitet sich aus und erscheint in der Peripherie tief eingeschnitten und unregelmässig. Mehr oder weniger lange Ausläufer vom granulirten Centrum ausgehend, umgeben sie. Andere ähneln einer Cocarde, einer sternförmigen Blume. In weicher Gelatine ist die Form der Colonieen äusserst abwechselnd.

Stichculturen in Traubenzuckergelatine haben eigentlich keine charakteristischen Merkmale. Zuerst erscheinen 2 bis 3 em unter der Oberfläche, dem Stich entlang, kleine weisse, runde Massen. Ist die Gelatine wenig fest, so strablen bald diese Massen nach allen Richtungen hin aus. Ringsherum verflüssigt sich der Nährboden allmählich. Eine starke Gasentwickelung tritt ein und in Folge dessen zerspringt die noch festgebliebene Gelatine in unregelmässige Klumpen, welche in der Röhre aufwärts getrieben werden bis gegen den Wattepfropfen, und nicht selten zum Theil mit letzterem aus dem Reagensglas geschleudert werden. Bleibt der Nährboden fest und unzerrissen, so steigen allmählich die Gasblasen sowie die verflüssigte Gelatine empor und bilden an der Oberfläche eine schäumende Schicht. Schliesslich ist die ganze Masse der Gelatine verflüssigt; am Boden des Röhrchens liegen nur gelblich-weisse, flockenartige Massen mit absolut klarer flüssiger Gelatine bedeckt, aus welcher während Wochen grosse Gasblasen aufsteigen.

In gewöhnlicher Gelatine oder mit ameisensaurem Natron ( 0.5 Procent) ist die Entwickelung charakteristischer; einige Centimeter unter der Oberfläche, dem Impfstich entlang; bilden sich dendritische, verzweigte Vegetationen, die Verflüssigung des Nährbodens schreitet sehr langsam fort und die Gasbildung ist unbedeutend.

Stichculturen in Zuckeragar bieten nichts Besonderes. Die Gaserzeugung ist sehr gross und in 24 bis 48 Stunden ist die ganze Masse in unregelmässige Klumpen gespalten.

Es ist kein widerlicher Geruch in Culturen auf Gelatine oder Agar nach wochenlanger Züchtung zu beobachten, sondern ein stark durchdringender Geruch von Buttersäure. 
In Nährböden mit Saccharose, Lactose u. s. w. ist das Wachsthum immer sehr dürftig und Gasbildung bleibt meistentheils ganz aus. Dasselbe Verhalten wird beobachtet in Gelatine, Agar u. s. w. ohne Traubenzucker, falls diese Nährböden durch Zusatz von Lakmus, Natriumindigoschwefelsäure für anaërobe Züchtung präparirt sind.

Trotz sorgfältiger Zubereitung und Abschluss der Luft durch Vacuum oder Wasserstoffdurchleitung ist kaum Wachsthum wahrnehmbar auf Kartoffeln und schräg erstarrtem Traubenzuckeragar oder Gelatine.

Glucosirte Bouillon trübt sich gleichmässig und entwickelt colossale Mengen Gas. Die Gaserzeugung hört nach 3 bis 4 Tagen bei $35^{\circ}$ auf und die Flüssigkeit klärt sich. Dagegen dauert sie bei 20 bis $25^{0}$ einige Wochen hindurch fort. Diese Culturen haben ebenfalls einen Buttersäuregeruch.

Die Milch gerinnt nicht, noch ändert sich nach langer Züchtung ihr Aussehen. Das Wachsthum selbst in alkalinisirter und auf's Sorgfältigste von Luft befreiter Milch bleibt stets spärlich. Wie schon gesagt, ist der Geruch nie widerlich; er erinnert nicht an Fäulniss, selbst bei Fleischculturen, peptonisirter Bouillon u. s. w. mit oder ohne Glucose. Der Geruch hat etwas Säuerliches, wie der der ranzigen Butter und ist dem des verdächtigen Schinkens ähnlich.

Die Zersetzungsproducte unseres Bacillus wurden bis jetzt noch nicht genau untersucht; eine orientirende Gasanalyse der producirten Gase ergab $\mathrm{H}, \mathrm{CO}_{2}$ u.s. w.

Damit die Cultur üppig fortschreitet und activ ist, muss ein gewisser Grad von Alkalescens vorhanden sein. Nach vielen Vorversuchen sind wir bei einer Alkalinität von 10 bis $15 \mathrm{~cm}$ der $\frac{\mathrm{N}}{10}$ Lösung $\mathrm{Na}_{2} \mathrm{CO}_{3}$ auf $100 \mathrm{cem}$ des Nährbodens stehen geblieben. Aber das Wachsthum verläuft noch reichlich in Gelatine, welche für $100=10^{\mathrm{cm}}$ normaler Lösung enthält.

Wir versuchten den Bacillus in eiweissfreien Nährlösungen zu züchten. Die Nährböden von Petermann, Maasen, Uschinsky, Proskauer und Beck zeigten keine Entwicklung. Wir nehmen somit an, dass unser Bacillus, ebenso wie Tetanus und andere pathogene Anaëroben, complicirtere Nährböden für sein Wachsthum verlangt, als z. B. Diphtherie und Tuberculose.

Der Schinkenmikroorganismus wächst bei ziemlich weit auseinander gehenden Temperaturen: unter $18^{\circ}$ ist die Entwickelung langsam und beschränkt; bei $20^{\circ}$ geht sie sehr üppig und schnell vor und wird gewöhnlich eine 15 bis $18 \mathrm{~cm}$ dicke Schicht Gelatine in 8 Tagen ganz verflüssigt. Das Optimum scheint zwischen 20 und $30^{\circ}$ zu liegen. In einem genau auf $\mathbf{3 8 . 5 ^ { 0 }}$ regulirten Brütapparat, fand man noch in Zuckeragar 
ziemlich zahlreiche Colonieen, jedoch war das Wachsthum im Verhältniss zu dem bei $35^{\circ}$ gering. Die feste Masse wurde nicht gesprengt; nach 24 bis 36 Stunden hörte die Entwickelung auf. Werden die Röhren nachher auf $20^{\circ}$ gebracht, so fängt oft eine üppige Gaserzeugung an. Dagegen ist es uns gewöhnlich nicht gelungen bei $38.5^{\circ}$ ein wahrnehmbares Wachsthum in der Traubenzuckerbouillon, nach Wasserstoffdurchleitung u. s. w. zu bekommen, wenn die Röhrchen zugeschmolzen werden. Aus dem Brütapparat herausgenommen und auf die gewöhnliche Temperatur gesetzt, zeigten sie schon nach 48 Stunden starke Trübung und Gaserzeugung. Einige Gläser jedoch trübten sich bei $38.5^{\circ}$; ein erklärlicher Grund für das Wachthum konnte nicht gefunden werden. Die bei 37 bis $38.5^{\circ}$ ausgewachsenen Mikroorganismen haben eine anomale Gestalt angenommen und stellen sehr lange Fäden dar mit unregelmässigem körnigen Inhalt und hier und da Verdickungen. Sporen sind nicht vorhanden und die Culturen mit diesen Involutionsformen sind wenig activ und verlieren ihre Lebensfähigkeit recht bald. (Vgl. Taf. I, Fig. 6.)

Man kann bei höheren Temperaturen, selbst bei $38.5^{\circ}$ hoch, ziemlich starke Entwickelung beobachten in Glucosebouillon, wenn man nur Sorge trägt für den leichten Abfluss der erzeugten Gase. Trotzdem nehmen die Bacillen die Fadenform an, und hört das Wachsthum nach wenigen Stunden auf. Aus diesen Versuchen lässt sich entnehmen, dass die Körpertemperatur der Warmblüter für die normale Entwickelung ungünstig ist, da schon von $35^{\circ}$ ab die Temperatur als dysgenetisch $\mathrm{zu}$ betrachten ist.

Der Schinkenbacillus ist ein obligater Anaërobe und erfordert daher bei der Züchtung besondere Sorgfalt. Aus dem flüssigen Nährboden muss man, um kräftige Culturen zu züchten, die Luft fast vollständig durch Vacuum oder ein indifferentes Gas austreiben. $\mathrm{CO}_{2}$-Durchleitung ist nicht gestattet; sie hat eine antiseptische Wirkung und verhindert absolut das Wachsthum in Gelatine-, Agar-, Bouillonröhrchen sowie auf Platten unter der Glocke. Nichts destoweniger kann die Entwickelung in den gewöhnlichen festen Nährböden wie Agar, Gelatine u. s. w. bei Zusatz ron 2 Procent Traubenzucker sehr üppig sein. Schweinefleisch, zerhackt und gekocht, nach Alkalisirung und Zusatz von Glucose (1 Procent), Pepton (1 Procent), NaCl (1 Procent) und Gelatine (2 Procent), bietet einen ausgezeichneten Nährboden dar, dessen man sich ohne besondere Cautelen für die Luftaustreibung bedienen kann, wenn man die noch kochende Fleischmasse mit zerschmolzenem Schmalz übergiesst.

Wie schon erwähnt, ist der Zusatz von 2 Procent Glucose in hohem Grade für das Wachsthum fördernd. Nicht nur begünstigt dieser 
Zusatz die Entwickelung der Bacillen, sondern auch die Giftproduction. Lactose, Glycogen, Stärke u. s. w. scheinen die Glucose in dieser Wirkung nicht vertreten zu können. Die in peptonisirtem Fleisch, Serum, Gelatine u. s. w. entwickelten Culturen waren stets wenig üppig, und fast unwirksam.

Ein Ueberschuss an $\mathrm{NaCl}$ hemmt das Wachsthum; Traubenzuckerbouillon bezw. -Gelatine mit 2 Procent Salz bleiben absolut klar. In Schweinefleiseh wird es sehr spärlich, sobald der Gehalt 5 Procent übersteigt, und ist gleich Null gegen 6 Procent. Das Pökeln, welches gewöhnlich in mindestens 10 procentigem Salzwasser statt. findet, sollte deshalb zum sicheren Schutz gegen jeden Unfall genügen, welchen das Vorhandensein unserer Mikroorganismen in Fleichwaren verursachen könnte.

Die Gelatineculturen behalten recht lange ihre Lebensfähigkeit; nach mehr als einem Jahr entwickeln sie sich noch auf neuem Nährboden. Die Sporen sind in der That sehr widerstandsfähig in nassem Zustand. In destillirtem Wasser aufgeschwemmt, an die Luft gebracht und zerstreutem Licht ausgesetzt, wurden sie noch nach 3 Monaten keimfähig befunden. Ausgetrocknet halten sie sich auch sehr lange lebend. Doch sind die Sporen dieses Bacillus verhältnissmãssig weniger resistent wie die meisten der bis jetzt bekannten Anaëroben, des B. tetani, B. oedematis maligni, B. des Rauschbrandes u. s. w. Nachdem Gelatine, Bouillonculturen, welche zahllose Sporen enthielten, während einer Viertelstunde bei einer Temperatur von ungefähr $85^{\circ}$ in zugeschmolzenen Capillarröhrchen erwärmt worden waren, entwickelten sie sich nicht mehr auf den gewöhnlichen festen Nährböden. Erhitzung auf $80^{\circ}$ während einer halben Stunde genügt vollkommen, um sporentragende Culturen sicher zu sterilisiren. Chemischen Agentien gegenüber zeigen sie ebenfalls nur einen geringen Widerstand; 5 procent. Carbolsäurelösung tödtet sie innerhalb 24 Stunden.

Der anaërobe Bacillus scheint in der Natur sehr wenig verbreitet zu sein. Wenigstens gelang es uns bis heute nicht, ihn in folgendem Material, welches anaërobe Verhältnisse darbietet, wiederzufinden. Wir untersuchten darauf hin: Fäces von Schwein, Kuh und Pferd, ron Fischen (Stör, Lachs u. s. w.), von Vögeln (Huhn, Ente, Taube u. s. w.), ferner Strassenschmutz, Stalldünger und Mistjauche u. s. w. Auch unsere Versuche mit Proben aus Ellezelles selbst, wo der Schinken herstammte, scheiterten sämmtlich.

Der aus dem Schinken, wie aus Leber, Milz, Blut der mit Maceration geimpften Thiere gezüchtete anärobe Bacillus ist bezüglich der 
auf verschiedenen Nährböden gewonnenen Culturen auf seine pathogene Wirkung geprüft worden; die Wirkung des aus der Milz eines der Opfer zu Ellezelles isolirten Mikroorganismus, welcher mit dem des Schinkens morphologisch identificirt wurde, wurde ebenfalls untersucht. Alle Versuche haben auf das Bestimmteste gezeigt, dass die bei den verschiedenen Thierarten durch den Schinkenbacillus und den aus der menschlichen Leiche isolirten Anaëroben hervorgerufenen Erscheinungen absolut dieselben sind.

Ferner haben wir uns durch zahlreiche Experimente überzeugen können, dass kein wesentlicher Unterschied besteht zwischen der Erkrankung, welche die Reinculturen hervorrufen und derjenigen, welche das verdächtige Fleisch verursacht. Wir können deshalb für die Beschreibung der Pathogenität unseres Mikroorganismus auf die sehr vollständige Darstellung der Schinkenvergiftung verweisen.

Höhere Dosen der Maceration von 5 bis $10^{\mathrm{ccm}}$ waren bei Kaninchen rom Magen aus noch nicht tödtlich. Ebenfalls brauchte man ziemlich grosse Mengen der Cultur, beispielsweise 10 bis $20 \mathrm{~cm}$ verflüssigter Gelatine, um dieses Thier innerhalb 48 Stunden zu tödten. Kleinere Dosen sind entweder wirkungslos oder es tritt Cachexie und später der Tod ein. Die Erscheinungen nach höheren Dosen waren dieselben: Speichelfluss, motorische absteigende Paresen, Dysphagie, Mydriasis u. s. w. Intensive Läsionen der Magenwand, Hämorrhagieen, Nekrose u. s. w. sind nicht selten bei diesen Thieren.

Das Meerschweinchen wird nach Einführung sehr kleiner Dosen per os schwer krank. Nach dem Genuss von 1 bis 2 Trüpfchen Gelatine oder Bouillon auf' ein Stückchen Brod, verendeten gewöhnlich die Thiere innerhalb 24 bis 36 Stunden unter ausgesprochenen paretischen Symptomen, Speichelfluss u. s. w. Die gastro-enteritischen Läsionen waren besonders entwickelt, wenn die Culturproducte in ziemlich grosser Quantität und bei nicht zu hoher Activität eingegeben wurden. Gewisse Gelatineculturen hatten eine blutige Entero-Colitis mit Schorfbildung hervorgerufen.

Sehr schnell starben auch die Mäuse nach Einnahme der kleinsten Mengen der verschiedenen Culturen auf Agar, Gelatine u. s. w. Eine deutliche Parese der hinteren Extremitäten wird oft beobachtet.

Wir haben uns bemüht, beim Affen ein Krankheitsbild hervorzurufen, dessen mehr chronischer Verlauf und Symptomencomplex mit dem beim Menschen beobachteten Bild des Botulismus übereinstimmen sollte. Leider sind wir mit den Culturversuchen nicht weiter gekommen wie bei den Schinkeuexperimenten. 
Wenig empfindliche. Thierarten, wie Ratten und Tauben, können enorme Mengen sehr activer Culturen verzehren, ohne die geringste Störung zu erfahren. Hunde, Hühner und Katzen haben Tage lang Schweinfleischculturen, deren Saft beim Kaninchen, subcutan injicirt, bei einer Dose von $0.0001 \mathrm{com}$ innerhalb 48 Stunden tödtlich war, gefressen und sind am Leben geblieben. Sie zeigten nur einige vorübergehende Erscheinungen, wie Erbrechen, leichten Durchfall, Anorexie u.s. w. Nur bei einer einzigen Katze, welche ohne zu erbrechen ungefähr 400 grm Fleischcultur auf einmal aufgefressen hatte, traten paretische Symptome, sehr deutliche und andauernde Pupillenerweiterung, Zungenprolaps, buccopharyngeale Hypersecretion, heisere Stimme u. s. w. auf. Ihr Gang war wankend wie bei Alkoholbetäubung. Nach einigen Tagen dieses Zustandes folgten cachektische Symptome und das Thier ging sehr abgemagert nach 5 Wochen zu Grunde. Wiederholt war der Stuhlgang blutig. Bei der Section fanden sich schwere ulceröse Veränderungen des Darmes und Dickdarmes.

Endlich können wir die absolute Unempfindlichkeit der Frösche und Fische, wie Cyprinus, bestätigen. Grosse Mengen der actirsten Bouillon, wurde ihnen ohne Erfolg eingegeben; die Thiere lebten munter weiter im Wasser, welches zahlreiche Sporen des anaëroben Bacillus enthielt.

Nach subcutaner Einspritzung der Culturen treten bei Tauben, Kaninchen, Meerschweinchen u. s. w. dieselben Symptome auf wie nach Injection der Schinkenmaceration. Bei dieser Applicationsweise eignet sich die Katze so ausgezeichnet für das Studium der Specificität des Schinkenbacillus wie für die des ursprünglichen Giftes dieses Fleisches. Diese Thierart hat uns ebenfalls den evidenten Beweis erbracht, dass die Ellezelles'sche Epidemie nur dem Vorhandensein eines specifischen Mikroorganismus in den genossenen Fleischwaaren zuzuschreiben ist. In zahlreichen Versuchen ist es wiederholt gelungen, die localisirten, fast pathognomonischen Paresen hervorzurufen, nämlich Zungenprolaps, Mydriasis, Aphagie, Aphonie u. s. w., so dass wir, im Gegensatz zu den meisten Autoren behaupten, dass der botulinische Symptomencomplex experimentell reproducirt werden kann. Uebrigens unterscheiden sich die beobachteten Symptome nicht von denen, welche im zweiten Theil ausführlich beschrieben wurden. Hohe Dosen, wie 5 bis $10^{\mathrm{eem}}$ einer 3 bis 4 Wochen alten Traubenzuckergelatine-Cultur oder Bouillon, tödten innerhalb 36 bis 48 Stunden nach einem Latenzstadium von ca. 6 bis 12 Stunden. Der Collaps und die allgemeine Parese treten rasch ein und die Thiere verenden mit Erstickungsanfällen, croupösem Husten, Pupillenerweiterung u. s. w. In diesen sehr acuten Fällen kann der Zungenprolaps ausbleiben. Nach kleineren Dosen, etwa 1 bis $5^{\mathrm{ccm}}$ Gelatine- 
cultur u. s. w., erscheinen die erwähnten Symptome, unter Anderen die verschiedenen Formen der partiellen Paresen, der Reihe nach, und der Tod erfolgt erst nach 6 bis 8 Tagen. Minimale Dosen endlich sind entweder wirkungslos oder rufen Cachexie hervor. Manche unserer Katzen starben erst nach Wochen oder Monaten im Marasmus. Einige zeigten während 7 bis 8 Wochen eine ausgesprochene Pupillenerweiterung, Aphonie, Motilitätsstörungen und wurden dann schliesslich gesund. Diese Thiere, sowie andere, welche mit wenig wirksamen, mit ameisensaurem Natron oder durch Temperatur abeschwächten Culturen injicirt wurden, zeigten sich bisweilen im hohen Grade refractär gegen wiederholte Impfung.

Hunde, Hühner u. s. w. sind ebenfalls fast immun oder reagiren nur auf eine Injection von 10 bis $30^{\mathrm{cem}}$ mit localer Eiterung, Abmagerung u. s. w.

Bei Kaninchen, Mäusen, Meersehweinchen genügen wirklich die minimalsten Dosen der verschiedensten Culturen, um die charakteristischen Erscheinungen nach subeutaner Injection hervorzurufen. Oefters dauerte der Speichelfluss bei Kaninchen und Meerschweinchen 3 bis 4 Wochen fort. Bei männlichen Thieren, deren Erkrankung sich in die Länge zog, zeigte sich mehrmals ein Penis-prolaps, welcher in verschiedenen Fällen bis zum Tode, 3 bis 4 Wochen lang anbielt.

Die Empfindlichkeit der Affen für die Culturproducte unseres Bacillus ist äusserst gross. Endlich, tritt nach subcutaner Injection der Taube ein recht charakteristischer Symptomencomplex auf: Parese der Flügel, Ptosis, grünliches Erbrechen u. s. w., wie wir schon früher bei den Schinkenexperimenten erwähnt haben.

Die beständige Anwesenheit der beschriebenen Tetradenart in dem Schinken, den menschlichen Organen, sowie den mit dem verdächtigen Fleisch geimpften Thieren könnte vermuthen lassen, dass dieser Mikroorganismus eine bestimmte Rolle bei den Vergiftungen gespielt habe. In der That ermöglicht der Micrococeus dem specifischen Flcischgiftbacillus das Wachsthum in nicht vollständig sauerstofffreien Medien dadurch, dass er den Sauerstoff für sich verbraucht. Zuckerbouillon, welche mit dem anaëroben Bacillus allein beschickt wird, trübt sich nie; wird dieselbe 8 Tage vorher mit dem Tetragenus geimpft, so erhält man eine sehr active Cultur. Setzt man jedoch filtrirte oder mit Chloroform behandelte Tetragenusculturen der Bouillon zu, so erhält man nicht dieselben Resultate, im Gegensatz zu ähnlichen Beobachtungen von Kedrowsky (64). Es scheint sich also wohl bei dieser Thatsache um Symbiose zu handeln.

Nach alledem scheint ${ }^{-e s}$ uns bewiesen, dass der isolirte anaërobe Bacillus als Krankheitserreger der Fillezelles'schen Fälle zu betrachten ist. 
Weitere Untersuchungen werden lehren müssen, ob dieser Mikroorganismus in den alimentären Vergiftungen, welehe sich durch dieselben Erscheinungen kennzeichnen, constant vorhanden ist - und werden also endgültig seine Rolle beim Botulismus, Ichthyosismus u. s. w. feststellen. Aber wir können schon jetzt behaupten, dass er mit aller Wahrscheinlichkeit der specifische Erzeuger dieser Erkrankungen ist, deren Ursache bis jetzt vergebens aufgesucht wurde.

Wir schlagen deshalb vor, dem anaëroben Bacillus des Ellezelles'sohen Schinkens den Namen Bacillus botulinus zu geben.

Die bei der Section der durch Culturen getödteten Thiere gefundenen makroskopischen Veränderungen der Organe sind fast absolut identisch mit denen, welche im Thierexperimente mit dem Schinken auftraten. Da wie hier fanden sich Hyperämie und kleine Hämorrhagieen der Verdauungsorgane, der Leber, der Nieren, des Centralnervensystems; Stauung der Galle, Urinretention; parenchymatöse Degeneration der Leber u. s. w. An den Injectionsstellen, selbst nach massiven Doser, werden bei den empfindlichen Thierarten nur geringe Extravasate oder ödematöse Infiltrationen beobachtet. Die resistenteren Thierspecies dagegen, wie Hund und Katze, zeigen Eiterung des subcutanen Gewebes. Nie wurde Nekrose constatirt. Bei Hübnern fehlt jede ausgesprochene locale Reaction.

Dr. van der Stricht hatte die Güte, eine systematische histologische Untersuchung mehrerer unserer Thiere vorzunehmen. Die Hauptorgane verschiedener Katzen, Meerschweinchen und Kaninchen, welche mit Schinkenmaceration oder Culturen, auf Porzellan filtrirt oder unfiltrirt injicirt wurden, sind in Serienschnitten studirt worden. Sie stammen alle, ausgenommen die von zwei Kaninchen, welche cachektisch verendeten, von Thieren, welche unter ganz acuten, charakteristischen Erscheinungen zu Grunde gegangen sind. Die Organe wurden spätestens 2 Stunden nach dem Tode durch Flemming, Hermann oder Sublimatlösung fixirt und mit Safranin oder Heidenhain'schem Haematoxylin gefärbt.

Das Studium des Nervensystems, die Aufsuchung nach der Nissl'schen Methode der feinsten Läsionen der Zellen in den Kernen der verschiedenen Centren hat der bekannte Neuro-Patholog, Herr Marinesco (65) für uns ausgeführt. Die Organe wurden stets frisch entnommen von Thieren, welche in verschiedenen Perioden getödtet waren.

Wir lassen nur einen kurzen Abriss der interessanten Ergebnisse dieser histologischen Untersuchung hier folgen. Er wird genügen, um die fast übereinstimmende Gleichheit der Histogenese der Läsionen, welche 
durch das primitive Schinkengift als auch durch die Culturen des B. botulinus oder seiner Toxine hervorgerufen sind, zu beweisen ${ }^{\mathbf{1}}$ ).

Der Magen zeigte stets Hyperämie mit desquamativer parenchymatöser Entzündung in der Gegend des Epithels der Drüsenöffnung. Bei einem Affen, der nach Schinkengenuss starb, bestehen gleichzeitig Spuren einer interstitiellen Entzündung. Die Congestion ist gewöhnlich von Hämorrhagieen in der Mucosa und von oberflächlichen Ulcerationen begleitet. Die Parietalzellen der Drüsenschläuche befinden sich mehrmals im ersten Stadium der körnigen, fettigen Degeneration.

Im Dünndarm findet sich Hyperämie, bisweilen kleine Blutextravasate und die Veränderungen einer mehr oder weniger ausgesprochenen Enteritis.

Die Leber ist hyperämisch und zeigt Blutgerinnsel, ferner interstitielle und parenchymatöse Entzündung mit fettiger Entartung der interlobulären Capillaren und der Leberzellen.

Die corticale und subcorticale Schicht der Niere ist gewöhnlich injicirt, theilweise mit kleinen Blutinfarcten. Desquamative Entzündung ist stets vorhanden, bisweilen auch fettige Degeneration der Zellen des Parenchyms. In der Gegend der Papillarschicht begegnet man Läsionen einer interstitiellen Entzündung.

Die Muskelfasern des Herzens können körnig-fettig degenerirt sein. Ausserdem bestehen noch Erscheinungen der interstitiellen Myocarditis. Dieselben Veränderungen findet man noch in anderen gestreiften Muskeln, Muskeln der Augen u. s. w. Die Iris dagegen war in drei Fällen vollkommen normal.

Bei den meisten Thieren hat das Volumen der Milz und die Zahl der Malpighi'schen Körperchen abgenommen, während die Pulpa durch zahlreiche Phagocyten vollgepfropft ist.

Lungen sind bisweilen entzündet oder hepatisirt. Im Knochenmark scheinen die Mastzellen abzunehmen und die eigentlichen Elemente des Parenchyms, die Leukocyten mit dunklem resp. hellem Protoplasma oder mit eosinophilen Granulis, die Megacaryocyten (66) und die Erythroblasten scheinen zu proliferiren. Zahlreiche Phagocyten werden dort getroffen.

Die submaxillaren Speicheldrüsen bei Katze, Kaninchen und Meerschweinchen sind verändert. Die mucösen Zellen sind fettig degenerirt, die Gianuzzi'schen Crescenten sebr ausgesprochen. Diese Andeutungen einer mucösen Degeneration der secretorischen Zellen waren in mehreren Fällen auf's Deutlichste vorhanden.

1 Vgl. Contribution à l'étude des intoxications alimentaires. - Recherches sur des accidents à caractères botuliniques. Archives de Pharmacodynamie. Vol. III. Fasc. 5 et 6. p. $534 \mathrm{ff}$. 
Beim Centralnervensystem sind die Läsionen in dem Grosshirn fast Null; sie fehlen in den Nervenfasern und sind sehr ausgesprochen im Rūckenmark, weniger in der Medulla oblongata, Protuberanz und Gehirnschenkel. Im Rückenmark und Pons sind sie fast ausschliesslich in dem Vorderhörner und Hinterhörner (motorische Kerne der Glieder und Bulbärkerne) vorhanden. Im ersten Stadium findet man nur in den Nervenzellen eine von der Peripherie ausgehende Verminderung der chromatophilen Elemente, später sind die Nissl'schen Körperchen in feine pulverartige Granula umgewandelt. Noch später entstehen Vacuolen durch Auflösung der achromatischen Substanz. Diese chromatolytischen Degenerationserscheinungen sind im Kern der N. hypoglossus, im Nuclens ambiguus, im Nucleus dorsalis des N. vagus, in den Purkinje'schen Zellen des Kleinhirns und im Mittelkern des 0calo-motorins beobachtet worden. Neben diesen regressiven Läsionen der Nervenzellen bestehen stets progressive Veränderungen des Gliagewebes. Die Gliazellen sind an mehreren Stellen vermehrt und spielen die Rolle von Neurophagen, indem sie die krankhaften Elemente wegschaffen. Endlich, seitens der Bluteapillaren treten auch constant hämorrhagische Herde, mehr oder minder diffus, interstitiell in der grauen Substanz der Hinterhörner, hauptsächlich der Bulbär- und der Oculomotoriuskerne auf.

Die eigentlichen Läsionen der Nervenzellen sind beobachtet worden bei Thieren, welche wie mehrere Katzen durch Subcutaninjection des Schinkens verendet sind oder mit Toxinen bezw. Culturen des B. botulinus inficirt wurden und scheinen bestimmt primitiver Art und durch ein Gift hervorgerufen zu sein. Sie stimmen in vielfaçher Hinsicht mit den Veränderungen überein, die bei an Rabies eingegangenen Thieren beobachtet wurden oder durch toxisch-infectiöse Mikroorganismen hervorgerufen sind, wie B. tetani. Jedoch kennzeichnent sich die feinere Nervenzellendegeneration, welche B. botulinus verursacht, durch Merkmale, deren Eigenthümlichkeiten auseinanderzusetzen hier nicht am Platze ist.

Im Besitz des Mikroorganismus, dem wir die Bildung des specifisehen Botulismusgiftes zuschreiben, waren wir genöthigt, die Frage zu entscheiden, ob die Krankheitserscheinungen auf einer echten Intoxication oder Infection beruhen. Wir wiederholen kurz die Versuche, welche beweisen, dass sich der Bac. botulinus im Thierkörper durchaus nicht zu vermehren im Stande ist.

Nachdem wir uns von der Wirksamkeit der durch Porzellan filtrirten Culturen überzeugt und ferner gesehen hatten, dass dieselben genau in denselben minimalen Dosen wirkten, wie die mit Bakterienkörper ver- 
sehenen Culturen, stellten wir zahlreiche mikroskopische und Culturversuche an, welche alle darauf hinwiesen, dass der Bac. botulinus sich weder im Exsudat, Leber, Milz, Nieren, Speicheldrüsen und Nervensystem, noch selbst im Intestinaltractus vermehrt. Er versehwindet schnell nach subcutaner, intravenöser und intraperitonealer Injection und ruft eine recht erhebliche Phagocytose hervor, genau so, wie es bei dem Bac. subtilis, einem der unschädlichsten Saprophyten der Fall ist.

Diese Thatsachen können uns jedoch immer noch nicht zu dem Schluss berechtigen, dem Bac. botulinus jegliche Infectiosität abzusprechen; möglicher Weise können wir weder die localen noch die allgemeinen Bedigungen im Thierversuch nachahmen, die die Fortpflanzungsfähigkeit des Bacillus im Thierkörper gestatten würde. Abgesehen von der hohen Wirksamkeit des Toxins könnte eine vorübergehende Vermehrung im Organismus, im Verdauungstractus u. s. w. stattfinden, die, wenn auch dem Nachweis sich entziehend, doch für eine tödtliche Infection ausreichen würde.

Wir versuchten zu diesem Zweck durch Auswaschen, Zusatz von Alkali, hohe Temperatur $\left(70^{\circ}\right)$ die Culturen ihres toxischen Principes zu befreien, ohne die vegetativen Eigenschaften der Bakterien zu schädigen. Ferner versuchten wir, die Bakterien gegen die Phagocytose durch Einhüllen in Agar zu schützen, oder Substanzen hinzuzufügen, die das Gewebe schädigen und die Leukocyten abhalten u. s. w.. Alle diesbezüglichen, wiederholten Versuche blieben resultatlos.

In analogen Versuchen haben Vaillard und Rouget (67) mit dem Tetanusbacillus, Besson (68) mit dem Oedembacillus im Gegentheil echte Infection bei Thieren hervorgerufen.

Es besteht also ein principieller Unterschied zwischen dem Bac. botulinus und der genannten pathogenen Arten. Ersterer ist ein Organismus, der jeglicher Virulenz in dem Sinne entbehrt, dass er nicht die Fähigkeit besitzt, sich im lebenden Thierkörper zu entwickeln. Er gehört demnach zu der wohlcharakterisirten, aber noch wenig zahlreichen Gruppe der pathogenen Saprophyten, die man die „toxicogenen" nennen könnte, zum Unterschied von den pathogenen, infectiösen Mikroben.

Es erübrigt noch, in Kürze die Ergebnisse einiger vergleichender Untersuchungen anzuführen, die wir mit einer filtrirten Cultur und dem daraus von Brieger (69) und Kempner (70) rein dargestellten Toxin erhalten haben. Die filtrirte Cültur tödtete in einer Dosis von $0.0005 \mathrm{~cm}$ ein Kaninchen in 60 bis 72 Stunden, ein Meerschweinchen in 4 bis 5 Tagen; bei Katzen rief eine Dosis von $0.5^{\mathrm{cm}}$ die charakteristischen Erscheinungen und den Tod in 8 bis 10 Tagen herror. Das rein dargestellte Toxin 
wurde in dem dem Ausgangsmaterial entsprechenden Volumen Wasser aufgelöst und war in denselben oben erwähnten Dosen wirksam. Dieses ausgefällte Gift scheint somit quantitatir und qualitatir das in den Culturen gelöste wirksame Princip zu enthalten.

Dem ganzen Charakter nach hat das Botulinusgift eine ausgesprochene Aehnlichkeit mit dem in dem Schinken von Ellezelles enthaltenen. Gleich der Maceration des Schinkens sind die filtrirten Culturen der Wärme gegenüber wenig resistent, sie verlieren ferner ihre Wirksamkeit unter Einfluss von Licht, Luft, Alkali, versehiedenen früher genannten Reagentien, und lassen sich durch Neutralsalze, Tannin, Zinkchlorid u. s. w. fällen.

Die bezüglich des Botulismus aufgedeckten Thatsachen scheinen uns wichtige Fingerzeige für die Prophylaxe zu geben. Die conservirten Nahrungsmittel, welche hauptsächtich der Anaërobiose ausgesetzt sind. dürfen niemals in rohem Zustande, sondern stets gehörig gekocht genossen werden.

Man muss von vornherein jegliches conservirte Nahrungsmittel vom Genuss ausschliessen, welches durch ranzigen. Geruch oder dergleichen Verdacht erregt. Es ist von Wichtigkeit, im Auge zu behalten, dass im Gegentheil die Nahrungsmittel, die durch den Geruch der Fäulniss Verdacht erregen, nicht die gefährlichsten sind.

Was nun den Schinken anbetrifft, so scheint eine genügend concentrirte Salzlake denselben gegen jegliche Verderb-. niss zu schützen.

In therapeutischer Hinsicht begreift man die Nutzlosigkeit der inneren Anwendung von Antisepticis, wie Resorcin, Salol u. s. w., die häufig empfohlen werden; andererseits hoffen wir auf die Möglichkeit einer serotherapeutischen Behandlung (71). 


\section{Litteratur.}

1. Eber. Instruction zur Untersuchung animaler Nahrungsmittel. Berlin 1895.

2. Müller, Das Wurstgift. Deutsche Klinik. 1869 u. 1870.

3. Johne. XXI. Jahresbericht des Landes-Medicinal-Collegiums über das Medicinalwesen im Königreich Sachsen auf das Jahr 1889. Leipzig 1891. - Bericht über das Veterinärwesen im Königreich Sachsen für das Jahr 1894.

4. Fischer, Ueber einige bemerkenswerthe Befunde bei der Untersuchung choleraverdächtigen Materials. Deutsche med. Wochenschrift. 1893. Nr. 24.

5. Poels u. Nolen, Vleeschvergiftingen te Rotterdam. Handeling van het Med. Natuur-en Geneeskunde Congres. 1894.

6. Holst, Bakt. Undersölgelser foretagne i anledning of Masseforgiftningen paa Gaustad Sindsygeasyl i 1891. Norsk. Mag. f. Lägev. 1894. Nr. 9.

7. Flügge, Zur Breslauer Fleischvergiftung. Zeitung für Fleisch-und Milchhygiene. 1894. S. 211. - Kän sche, Zar Kenntniss der Krankheitserreger bei Fleischvergiftungen. Diese Zeitschrift. 1896. Bd. XXII.

8. Günther, Bakteriologische Untersuchungen in einem Falle von Fleischvergiftung. Archiv für Hygiene. 1896. Bd. XXVIII.

9. Silberschmidt, Ueber eine Fleischvergiftung. Correspondenzblätter für Schweizer Aerzte. 1896. Nr. 8.

10. G. Pouchet, Bactériologie appliquée à la médecine légale. Ann. d'Hygiène publique et de méd. légale. Mars 1897.

11. E. van Ermengem, Recherches sur les empoisonnements produits par de la viande de veau à Moorseele. Bull.Acad. med. de Belgique. 1892. - Des intoxications alimentaires. Ebenda. 1895. - Recherches sur des cas d'accidents alimentaires produits par des saucisses. Revue d'Hygiène. 1896. Nr. 9.

12. Müller, a. a. 0 .

13. Husemann, Wurstgift. Realencyclopädie der ges. Heilkunde. 1883. Bd.XV.

14. Böhm. Handbuch der Intoxicationen. - v. Ziemssen's Handbuch der speciellen Pathologie $u$. Therapie. 1880. 2. Aufl.

15. Senckpiehl, Ueber Massenerkrankungen nach Fleischgenuss, besonders durch Wurst und Fleischgift. Inaugural-Dissertation. Berlin 1887.

16. Huseman n, a. a. O. - Handbuch der Toxicologie. 1862. I. Hältte. S. 327.

17. Böhm, a. a. O. S. 243.

18. Roth, Zwei Fälle von Wurstvergiftung (Botulismus). Vierteljahrsschrift für gerichtl. Medicin und öffentl. Sanitätswesen. 1883. Bd. XXXIX.

19. Roth, a. a. O.

20. Uhlrich, Fünf Fälle von Fleischvergiftung in einer Familie. Klinische Monatsblätter für Augenheilkunde. Juli 1882. Jahrg. XX.

21. Groenouw, Fünf Fälle von Accommodationslähmung bei Fleischvergiftung (Schinken). Ebenda. Mai 1890. Jahrg. XXVIII.

22. de Visscher, De l'importance des ptomaïnes pour la médecine légale. Verhandlungen des $X$. intern. med. Congresses. Bd. V. Abth. 7. Gerichtl. Medicin. S. 28. - Remarques au sujet de deux empoisonnements ptomaïniques. Ann. Soc. méd. legale de Belgique. 2. Ann. 1890. 
23. du Mesuil, Relation de 11 cas d'empoisonnements par de la viande de conserve de boeuf alterée. Thèse du Doctorat. Lorient 1875. - Annales d'Hygiène publique. T. XLIII. Sér. II. p. 472.

24. Quincke, Ueber Fleischvergiftung. Deutsche med. Zeitschr. 1885. Nr. 65.

25. Cohn, Sehstörungen bei Vergiftungen durch Wildpastete und Hecht. Archiv für Augenheilkunde. 1880. Bd. IX. S. 148.

26. Scheby-Busch, Bericht über 38 Fälle von Accommodationslähmung aus den Kieler Kliniken. Archiv für Ophthalmologie. Bd. XVII. S. 283.

27. Fall von Ungefug. Vgl. Senckspiehl, a. a. O.

28. Flury, Zur Casuistik der Fleischvergiftung. Correspondenzbl. f. Schweizer Aerzte. $1885 . \mathrm{Nr} .8$ u. 9.

29. Cohn, a. a. O. S. 159.

30. Schreiber, Ueber Fischvergiftung. Berliner klin. Wochenschrift. 1884. Nr. 11 u. 12.

31. Hirschfeld, Fünf Fälle von Fischvergiftungen mit drei Todesfällen. Vierteljahrsschrift für gerichtl. Medicin. 1885. Bd. XLIII. S. 283.

32. A lexander, Ueber Fischvergiftung mit Vorstellung von Kranken. Berliner ärztliche Zeitschrift. 1888. Nr. 3.

33. v. Anrep, Intoxication par les ptomaïnes. Archives slaves de Biologie. 1886. T. I. p. 341.

34. Arustam off, Ueber die Natur des Fischgiftes. Vorläufige Mittheilung. Centralblatt für Bakteriologie. 1891. Bd. X. Nr. 4. S. 116.

35. S. Sch midt, Zur Frage über die Natur des Fischgiftes und dessen Wirkung auf den menschlichen und thierischen Organismus. Verhandlungen des $X$. intern. med. Congresses. 1891. Bd. II. S. 43.

36. Brosch, Zur Casuistik der Fischvergiftung. Tödtliche Austernvergiftung. Wiener klin. Wochenschrift. 1896. Nr. 13.

37. Springfeld, Ueber Vergiftungen durch den Genuss von niederen Seethieren vom Standpunkt der Sanitätspolizei. Vierteljahrsschrift für öffentl. Gesundheitspflege. 1895. Bd. XXVI. S. 354.

38. Virchow, Ueber die Vergiftung durch Miẹsmuscheln in Wilhelmshaven. Berliner klin. Wochenschrift. 1888. Nr. 48.

39. Wolff, Ueber das Gift der Miesmuscheln. Archiv für patholog. Anatomie. Bd. CIII u. CX.

40. Vgl. Salkowsky, Zur Kenntniss des Giftes der Miesmuscheln. Ebenda. 1889. Bd. CII.

41. Souchay, Zur Kenntniss der Wurstvergiftung. Inaug.-Diss. Tübingen 1889.

42. Schreiber, a. a. 0 .

43. v. Anrep, a. a. O. S. 353.

44. Schlossberger, Das Gift verdorbener Würste mit Berücksichtigung seiner Analogen in anderen thierischen Nahrungsmitteln. Erster Artikel. Archiv für physiologische Heilleunde. Supplm. 1892. Bd. I. S. 709.

45. Ehrenberg, Ueber einige in einem Falle von sogen. „Wurstvergiftung“ ans dem schädlichen Materiale dargestellte Fäulnissbasen, sowie über einige durch Thätigkeit eines besonderen in gleichen Materialien aufgefundenen Bacillus gebildete Zersetzungsproducte. Zeitschrift für physiol. Chemie. 1887. Bd. XI. S. 239.

46. Brieger, Untersuchungen über Ptomä̈ne. 1889. S. 33.

47. Bisch off, Auszug aus dem Gutachten des gerichtlichen Chemikers Hrn. Prof. Bisch off. Vierteljahrsschrift für gerichtl. Medicin. 1889. Nr. 43. S. 290. 
48. v. Anrep, a. a. 0 . S. 341.

49. Vgl. Kobert. Lehrbuch der Intoxicationen. 1893. S. 616.

50. Eichenberg, Ueber Vergiftung durch Wurstgift im Anschluss an beobachtete Fälle. Inaugural-Dissertation. Göttingen 1880.

51. Nauwerck, Ueber Wurstvergiftung. Med. Correspondenzbl. des Württbg. ärztl. Landesvereins. 1886. Bd. LVI. Nr. 20. - Ueber Wurstvergiftung. Münchener med. Wochenschrift. 1886. Nr. 30.

52. Vgl. Seraffini, Chemisch-bakteriologische Analyse einiger Wurstwaaren. Archiv für Hygiene. 1891. Bd. XIII. - Beetjen, Ueber Bakterien der Wurst. Inaugural-Dissertation. Würzburg 1890.

53. Vgl. v. Anrep, a. a. 0 .

54. Arustam off, a. a. 0 .

55. Purckhauer, Zur Casuistik der Allantiosis. Breslauer ärztl. Intelligenzbl. 1887. Nr. 24. S. 257.

56. Kaatzer, Ueber Vergiftung durch Wurstgift. Deutsche med. Wochenschrift. 1881. Nr. 7.

57. Groenouw, a. a. O.

58. Casselmann, Ueber einen Versuch hinsichtlich der Wirkung angeblich giftiger Fische auf eine Katze. Pharm. Zeitung für Russland. 1871. Nr. 7.

59. Hu semann, Artikel Wurstgift. A. a. O. S. 4.

60. Brieger u. C. Cohn, Untersuchangen über das Tetanusgift. Diese Zeitschrift. 1893. Bd. XV. S. 8.

61. v. Ermengem, Ueber Fälle von Fleischvergiftung mit Symptomen von Botulismus. Centralblatt für Bakteriologie. 1896. Bd. XIX. S. 442.

62. L. de Koninck, Nouvel appareil pour la préparation dal' acide chlorhydrique, etc. Revue univ. des mines. 1893. Vol. XXIV. p. 73.

63. v. Ermengem, Eine neue Methode der Cilienfärbung. Zeitschrift für wiss. Mikroskopie. 1895. Bd. XI.

64. Kedrowsky, Ueber die Bedingungen, unter welchen anaërobe Bacillen anch bei Gegenwart von Sauerstoff existiren können. Diese Zeitschrift. 1895. Bd. XX. S. 398.

65. Vgl. Marinesco, Pathologie générale de la cellule nerveuse. Lésions sécondaires et primitives. Presse médicale. 1897. Nr. 8.

66. van der Stricht, Nouvelles recherches sur la genèse des corpuscules rouges et des globules blancs du sang. Archives de biologie. 1892. Vol. XII. Fasc. 2.

67. Vaillard u. Rouget, Contribution à l'étude du tétanos. Annales de l'Institut Pasteur. 1892. Nr. 6.

68. Besson, Contribution à l'étude du vibrion septique. Ebenda. 1895. Nr.4. p. 179 .

69. Brieger und Boer, Ueber die Toxine der Diphtherie und des Tetanus. Deutsche med. Wochenschrift. 1896. Nr. 49.

70. Brieger u. Kempner, Beitrag zur Lehre der Fleischvergiftung. Ebenda. 1897. Nr. 32.

71. Kempner n. Pollack, Die Wirkung des Botulismustoxins und seines specifischen Antitoxins auf die Nervenzellen. Ebenda. 1897. Nr. 31. 
56 E. van Ermengtam: Über hinen neden anä̈roben Bacillus.

\section{Erklärung der Abbildungen.}

(Taf. I-III.)

\section{Tafel I.}

Fig. 1. Schinken. - Schnitt durch Muskel- u. Bindegewebe. Sporen. $\times 1000$. Fig. 2. Schinken. - Desgleichen.

Fig. 3. Bac: botulin us. -8 tägige Cultur in Zuckergelatine. $\times 1000$.

Fig. 4. Bac. botulinus. - Desgl. Sporen und Bacillen. $\times 1000$.

Fig. 5. Bac. botulinus. - Desgl. Freie Sporen. $\times 1000$.

Fig. 6. Bac. botulinus. - Bouilloncultur, 48 Stunden alt, bei $38^{\circ} 5^{\circ}$. Involutionsformen. $\times 1000$.

\section{Tafel II.}

Fig. 1. Katze Nr.60. - Inoculirt mit $1^{\mathrm{cem}}$ Bonilloncultur des Bac. botulinus. Fig. 2. Affe III. - Ingestion von $2^{\mathrm{ccm}}$ Maceration.

\section{Tafel III.}

Fig. 1. Kaninchen Nr. 79. - Inoculirt mit $0 \cdot 001 \mathrm{~cm}$ Schinkenmaceration.

Fig. 2. Taube Nr. 8. - Inoculirt mit 1 com derselben. 
1.

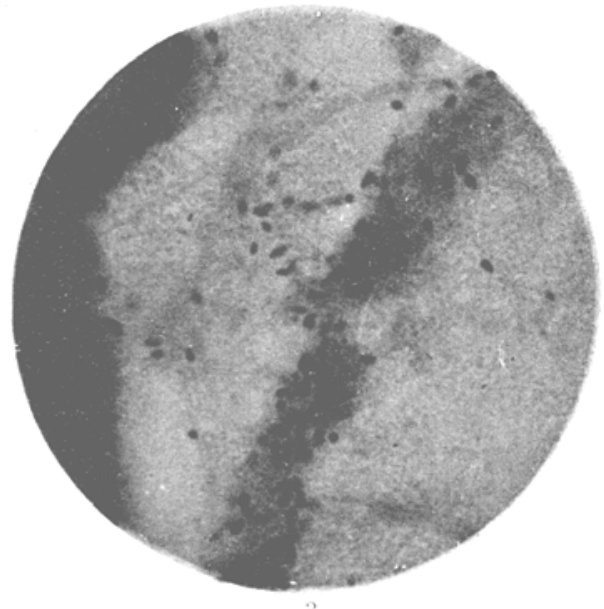

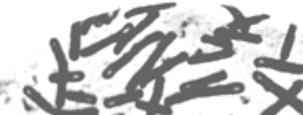

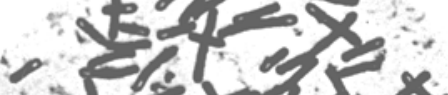

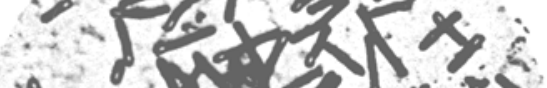

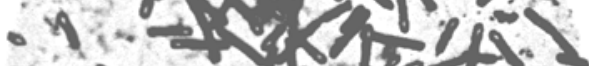

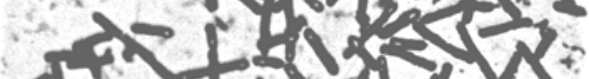

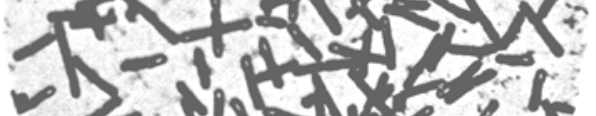

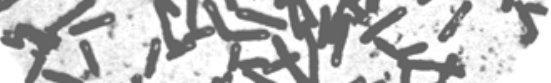
ent? (1)

$-85.000$.

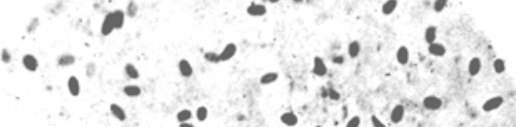

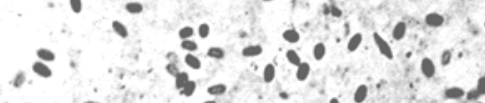

-0 - 0 0 o

- o $0.5 \%$

$+1$

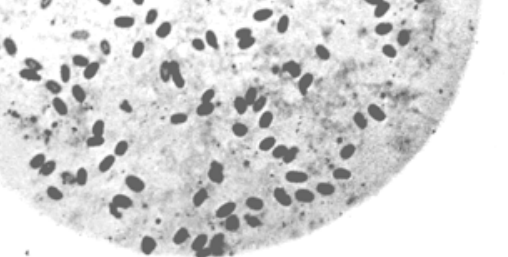

Verlag ron Veit \& Comp., Leipzic.
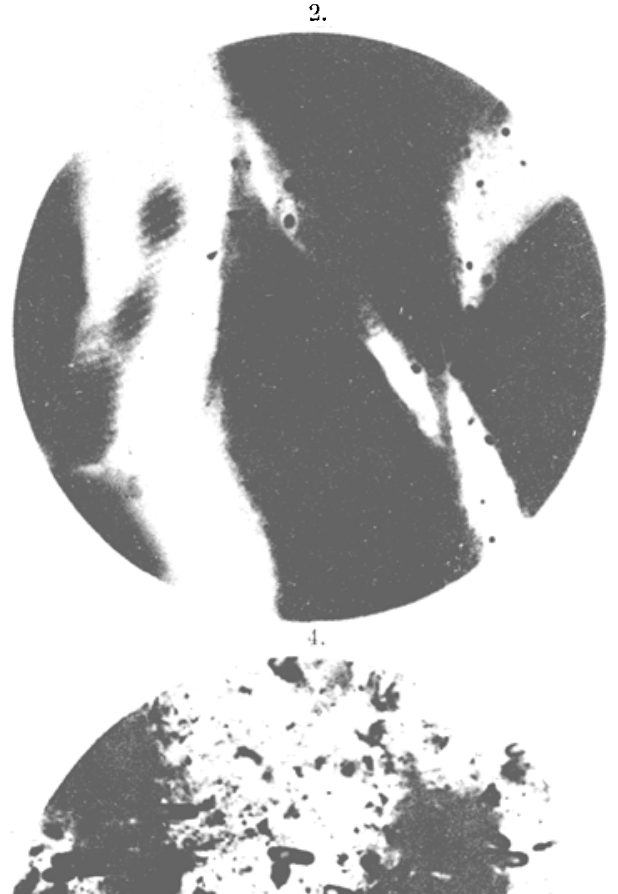

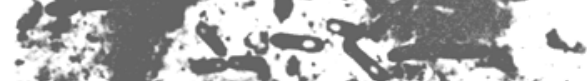

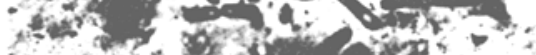

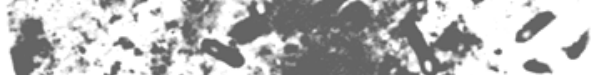
3. 4 r if a

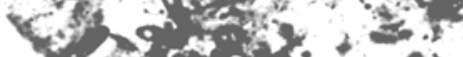

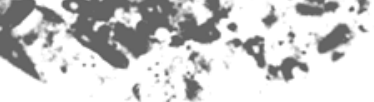

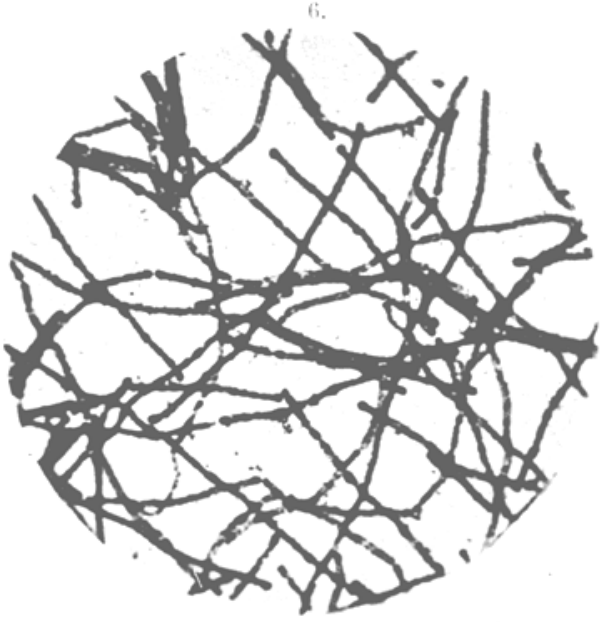

Lichtdruck Mcisenbach, Miffrth \& Co., Berlin. 
Zeitschrift für Hygiene Bd. XXVI.

Taf. II.
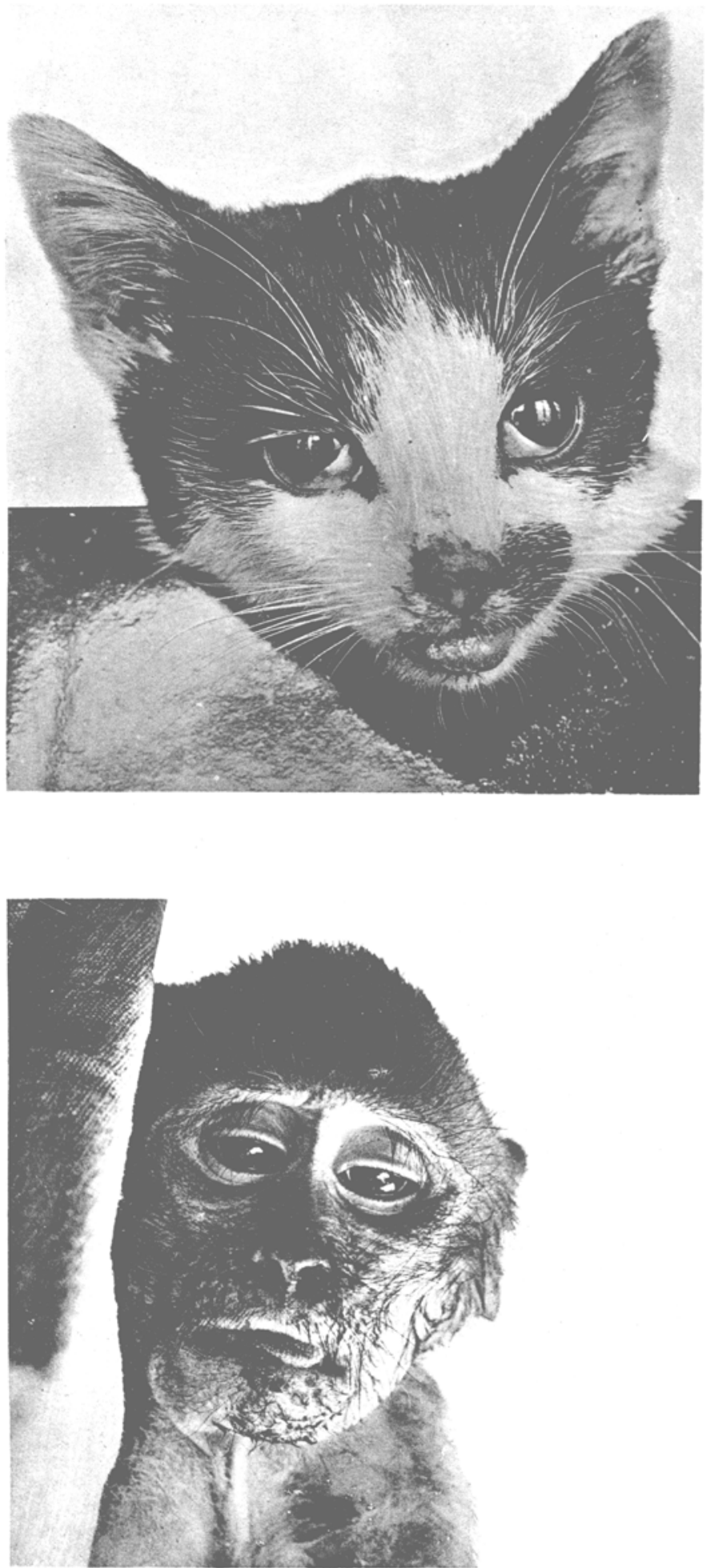

Verlag ron Veit Comp., Leipzig.

Lichtdruek Meisenbach, Riffarth \& Co. 

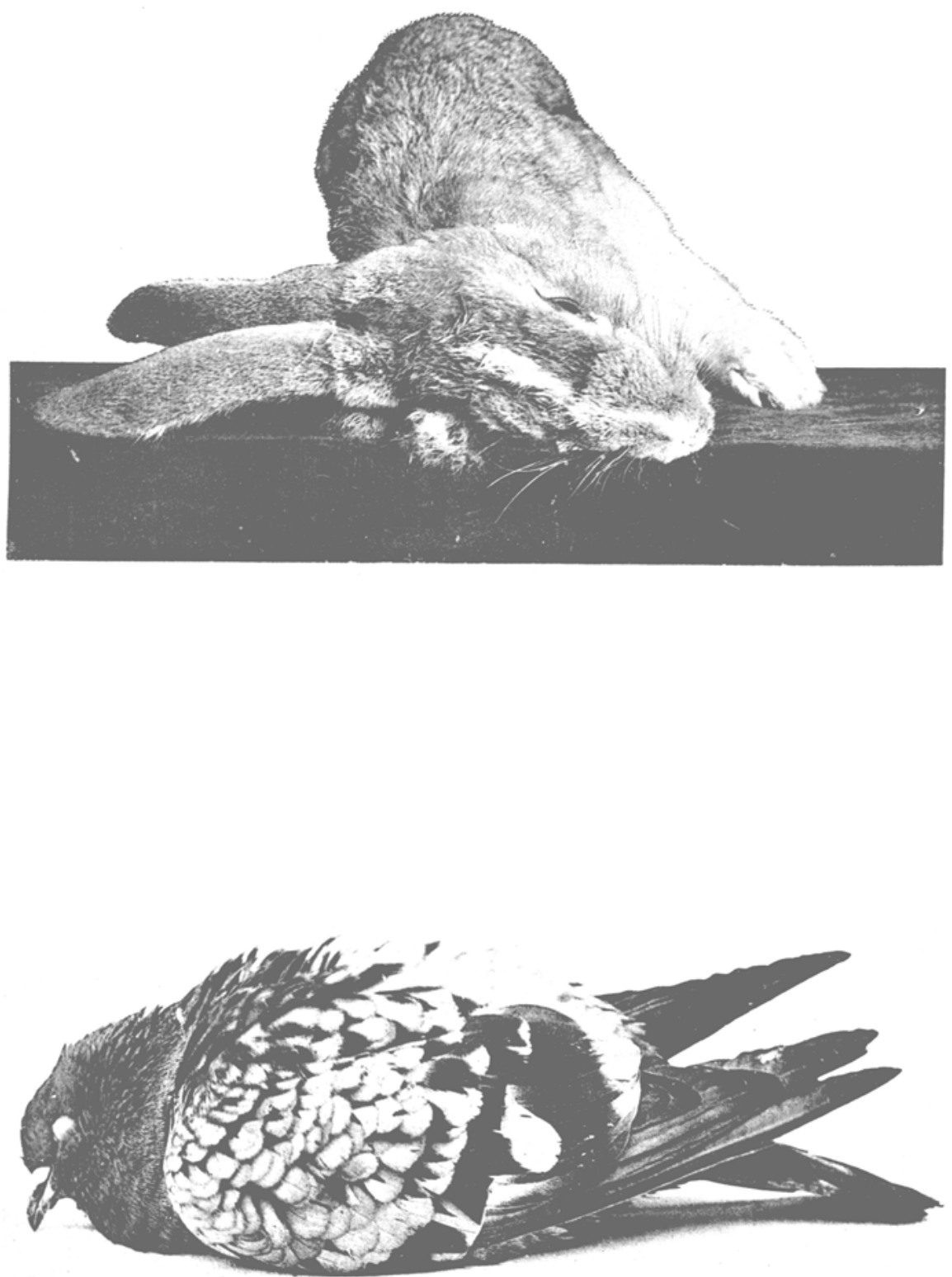